\title{
CFD-based shape optimization of steam turbine blade cascade in transonic two phase flows
}

\author{
S. M. A. Noori Rahim Abadi ${ }^{1}$, A. Ahmadpour ${ }^{*}{ }^{2,}$ S. M. N. R. Abadi $^{2}$, J. P. Meyer ${ }^{1}$ \\ ${ }^{1}$ Department of Mechanical and Aeronautical Engineering, University of Pretoria, Pretoria, South Africa \\ ${ }^{2}$ Department of Mechanical Engineering, Amirkabir University of Technology, Tehran, Iran \\ "Corresponding Author Email: ali.ahmadpour@aut.ac.ir; Tel: +982164543455; Fax: +982166419736; Address: 424 \\ Hafez Ave., P.O. Box 15916-34311, Tehran, Iran
}

\section{Highlights}

- CFD-based shape optimization of a nozzle and a turbine blade regarding nucleating steam flow is performed.

- Nucleation rate and droplet radius are the best suited objective functions for the optimization $\mathrm{p}$ rocess.

- Maximum 34\% reduction in entropy generation rate is reported for turbine cascade.

- A maximum $10 \%$ reduction in Baumann factor and a maximum $2.1 \%$ increase in efficiency is achieved for a turbine cascade.

\begin{abstract}
:
In this study CFD-based shape optimization of a 3D nozzle and a 2D turbine blade cascade is undertaken in the presence of non-equilibrium condensation within the considered flow channels. A two-fluid formulation is used for the simulation of unsteady, turbulent, supersonic and compressible flow of wet steam accounting for relevant phase interaction between nucleated liquid droplets and continuous vapor phase. An in-house CFD code is developed to solve the governing equations of the two phase flow and was validated against available experimental
\end{abstract}


data. Optimization is carried out in respect to various objective functions. It is shown that nucleation rate and maximum droplet radius are the best suited target functions for reducing thermodynamic and aerodynamic losses caused by the spontaneous nucleation. The maximum increase of $2.1 \%$ in turbine blade efficiency is achieved through shape optimization process.

Keywords: Two-fluid model; wet steam; non-equilibrium condensation; Steam turbine; Shape optimization.

\section{Nomenclature:}

E Total energy (J)

f Objective function

F Interface forces $(\mathrm{N})$

g non-equality constraint

$\mathrm{H} \quad$ Total enthalpy $(\mathrm{J} / \mathrm{kg})$

$\mathrm{h}_{\mathrm{c}} \quad$ Heat transfer coefficient $\left(\mathrm{W} / \mathrm{m}^{2} . \mathrm{k}\right)$

J Nucleation rate $\left(1 / \mathrm{m}^{3} \cdot \mathrm{s}\right)$

$\mathrm{k} \quad$ turbulent kinetic energy $\left(\mathrm{m}^{2} / \mathrm{s}^{2}\right)$

Kn Knudsen number

M Mass of one molecule of water $(\mathrm{kg})$

$\mathrm{n} \quad$ Number of droplet per unit mass of vapor (\#1/kg)

$\mathrm{P} \quad$ Pressure $(\mathrm{Pa})$

Pr Prantdl number

$\mathrm{r} \quad$ droplet radius $(\mathrm{m})$ 
R Gas constant (J/kg.K)

REG Reduction in Entropy Generation

RMDD Reduction in Maximum Droplet Diameter

$\mathrm{t} \quad$ Time (s)

T Temperature $(\mathrm{K})$

u Velocity $(\mathrm{m} / \mathrm{s})$

x Cartesian direction (m)

y Liquid mass fraction

\section{Greek symbols:}

$\lambda$ Thermal conductivity (W/m.K)

$\sigma \quad$ Surface tension $(\mathrm{N} / \mathrm{m})$

$\Gamma \quad$ Mass transfer rate $\left(\mathrm{kg} / \mathrm{m}^{3} . \mathrm{s}\right)$

$\alpha \quad$ Liquid volume fraction

$\tau \quad$ Stress tensor $\left(\mathrm{N} / \mathrm{m}^{2}\right)$

$\rho \quad$ Density $\left(\mathrm{kg} / \mathrm{m}^{3}\right)$

$\varepsilon \quad$ turbulent dissipation rate $\left(\mathrm{m}^{2} / \mathrm{s}^{3}\right)$

$\bar{l} \quad$ Free molecular pass (m)

$\mu \quad$ Viscosity (Pa.s)

$\eta \quad$ Blade efficiency

\section{Subscript:}

$1 \quad$ Liquid 


$\begin{array}{ll}\mathrm{v} & \text { Vapor } \\ \mathrm{m} & \text { Mixture } \\ \mathrm{lv} & \text { liquid-vapor } \\ \text { int } & \text { Interface } \\ \text { sat } & \text { Saturation } \\ \mathrm{s} & \text { Isentropic }\end{array}$

\section{Superscript:}

* Critical condition

\section{Introduction}

The usage of industrial steam turbines with several stages is ubiquitous in fossil-fired and nuclear power plants. When high pressure steam flows through consecutive stages of a steam turbine, its pressure and temperature drops sharply. Eventually and within final stages of the turbine, vapor becomes supersaturated (with local pressure levels higher than the vapor pressure at the corresponding mixture temperature) and non-equilibrium condensation stems from homogenous ( or in the presence of foreign impurities heterogeneous) nucleation. Due to high velocity of the bulk flow, a thermodynamic equilibrium will not be reached by the vapor and liquid droplets within the blade cascade and a non-negligible temperature difference is observed between these two phases alongside velocity slip. The presence of water droplets in gas flow (wet steam) yields to three major losses [1]:

(1) Thermodynamic losses (due to heat transfer between liquid phase and gaseous phase and its associated entropy generation) 
(2) Aerodynamic losses (due to formation of a liquid layer on the top of turbine blades and large droplets formed at the trailing edge of blades and their interaction with the bulk flow and possible shock waves through drag force)

(3) Erosion losses (due to high velocity water droplets which impact the surface of turbine blade)

These three losses are collectively called wetness or moisture losses which degrade the overall performance of a steam turbine in comparison with a dry working condition (a rule of thumb states that $1 \%$ loss in efficiency for every $1 \%$ wetness fraction) [1]. According to the experimental measurements conducted by white et al. [2], the wetness loss in the last stages of steam turbines is comparable to the magnitude of the viscous loss. Therefore, the study of transonic two-phase flows (wet steam flows) through last stages of steam turbines has become an active field of research for at least 4 decades. These studies have tried to explore the physics of such a complicated flowing phenomenon in order to devise new techniques for reducing wetness loss or equivalently increasing the turbine efficiency.

For the study of two-phase transonic flows, computational fluid dynamics (CFD) has been established as a reliable predictive tool. The necessary groundwork for developing powerful numerical method for wet steam flows with non-equilibrium condensation was provided by the experimental data for nucleating flows in nozzles and turbine cascades [3-5]. Among one the first successful attempt to tackle the 2D transonic wet steam flow problem, one could mention the work by Gerber and Kermani [6] whom have developed a model for homogenous nucleation in high-speed flows based on an Eulerian-Eulerian description of two phase flow and the classical nucleation theory. 
Dykas et al. [7] highlighted the importance of using real gas model in simulation of transonic wet steam flows in order to obtain reasonable estimation for thermodynamic losses. More comprehensive results presented by Nikkhahi et al [8] portrayed the capability of EulerianEulerian description of gaseous phase and water droplets in accurate prediction of pressure distribution around a 2D turbine's rotor tip. Wroblewski et al. $[9,10]$ proposed and validated a new theoretical treatment for heterogonous condensation of wet steam in the low pressure part of large power turbines for 2D and 3D turbine geometries when insoluble impurities like $\mathrm{NaCl}$ are present in the steam flow.

The effect of back pressure on the non-equilibrium condensation through a turbine cascade was studied numerically and experimentally by Yousif et al. [11]. It was reported that low back pressure causes a high level of liquid mass fraction for a wide range of inlet conditions. Moreover, a favorable agreement was reported between numerical solution and experimental measurements.

Dykas and Wroblewski [12] presented a two-fluid formulation for homogenous condensing flow accounting for gas flow turbulence and compressibility together with slip velocity at the gas/liquid interface neglecting the viscosity of water phase. They successfully implemented their formulation into an in-house CFD code for simulating the transonic two phase flow thorough a 2D blade cascade. Significant velocity slip is reported around the trailing edge of turbine blade and the sign of slip velocity varies in different areas of flow channel due to local characteristics of compressible two phase flow. Condensing flow through an entire last stage of a nuclear steam turbine with long-spanned blades were studied in Ref. [13], where three liquid phases were considered to account for water droplets at the inlet of the stage, nucleated droplets in the rotor 
and nucleated droplets in the stator. The variation of wetness fraction and enthalpy drop across the blade span was presented.

A 3D numerical simulation of wet steam flow through stationary and moving blades of a steam turbine was carried out by $\mathrm{Yu}$ et al. [14]. The main motivation behind the study was the examination of the adverse effect of liquid droplet deposition (onto turbine blade) on the performance of the turbine. Dykas et al. [15] carried out detailed experiments on transonic wet steam flows through two different geometries, a Laval nozzle and a stationary linear blade cascade. As a major finding, the formation of coarse water droplets prompted by shock waves was reported near the outlet of the nozzle and at the trailing edge of blades. The experimental results were compared to a series of numerical simulation performed by an in-house code based on unsteady RANS formulation together with SST k- $\omega$ turbulence model. The volume of vapor, droplet interaction and the velocity slip between liquid and gaseous phases were neglected to obtain a one-fluid formulation based on continuous droplet growth model. A good agreement was detected between calculated and measured static pressures for both geometries. However, the location of shock waves in blade cascade is slightly shifted downward in numerical simulation due to the inability of the developed code to capture the thin water film flowing on the side of solid blades.

A review of numerical simulations cited above reveals that numerical method for the transonic wet steam flow with non-equilibrium condensation has become mature enough to be used for shape optimization (aimed at obtaining minimum wetness loss) of flow passages in which spontaneous condensation occurs. The shape optimization is carried out successfully for a 1D nozzle geometry in $[16,17]$ using proper numerical two phase flow solvers. To best of our knowledge, no attempt was reported to optimize the profile of a turbine blade cascade in 
presence of non-equilibrium condensation. Therefore, in this work, we are aimed to utilize an inhouse numerical two phase flow solver (which its suitable performance has been proved previously [18-20]) to optimize the profile of a 2D turbine blade cascade and a $3 \mathrm{~d}$ nozzle accounting for homogenous nucleation of water droplets in gas flow and the velocity slip between gas and liquid phases. The optimization will be carried out in respect to various relevant objective functions and the performance of each optimization attempt will be evaluated based on proper parameters which could measure the wetness loss in the presence of condensation. Moreover, the effect of shape optimization will be investigated in detail on the main feature of wet steam flow across nozzles and stationary blade cascade.

To achieve our goal, a two-fluid formulation is employed together with the classical nucleation and growth model accounting for vapor and droplet mixture departure from thermodynamic equilibrium. The Genetic Algorithm (GA) is used as the global optimizer with various objective functions to modify the shape of turbine blades in order to ultimately achieve a better performance for the entire blade cascade and turbine. Moreover, in this study the characteristic parameters of non-equilibrium condensation phenomenon are considered as objective functions in GA method for the optimization of steam blade profile for the first time.

The manuscript is organized as follows: in section two and three, the governing equations for wet steam transonic flow with condensation are presented. The details of the numerical method employed in this work is given in section 4 followed by numerical results for a 3D nozzle and a 2D turbine cascade. Finally, the work is concluded by highlighting its major findings. 


\section{Governing Equations}

In this study, a two fluid model is adopted in which the continuity, momentum and energy conservation equations are solved for each phase separately. The governing equations for the gaseous phase are given by:

$$
\begin{aligned}
& \frac{\partial\left(\rho_{\mathrm{v}}(1-\alpha)\right)}{\partial \mathrm{t}}+\frac{\partial\left(\rho_{\mathrm{v}}(1-\alpha) \mathrm{u}_{\mathrm{vj}}\right)}{\partial \mathrm{x}_{\mathrm{j}}}=-\left(\Gamma_{1}+\Gamma_{2}\right) \\
& \frac{\partial\left(\rho_{\mathrm{v}}(1-\alpha) \mathrm{u}_{\mathrm{vi}}\right)}{\partial \mathrm{t}}+\frac{\partial\left(\rho_{\mathrm{v}}(1-\alpha) \mathrm{u}_{\mathrm{vj}} \mathrm{u}_{\mathrm{vi}}+(1-\alpha) \mathrm{p} \delta_{\mathrm{ij}}\right)}{\partial \mathrm{x}_{\mathrm{j}}}-\frac{\partial\left((1-\alpha) \tau_{\mathrm{ij}}\right)}{\partial \mathrm{x}_{\mathrm{j}}} \\
& =-\left(\Gamma_{1}+\Gamma_{2}\right) \mathrm{u}_{\mathrm{int}}-\mathrm{F}_{\mathrm{Di}}-\mathrm{p} \frac{\partial \alpha}{\partial \mathrm{x}_{\mathrm{i}}} \\
& \frac{\partial\left(\rho_{\mathrm{v}}(1-\alpha) \mathrm{E}_{\mathrm{v}}\right)}{\partial \mathrm{t}}+\frac{\partial\left(\rho_{\mathrm{v}}(1-\alpha) \mathrm{u}_{\mathrm{vj}} \mathrm{H}_{\mathrm{v}}\right)}{\partial \mathrm{x}_{\mathrm{j}}}+\frac{\partial\left((1-\alpha) \mathrm{q}_{\mathrm{vj}}-(1-\alpha) \mathrm{u}_{\mathrm{vj}} \tau_{\mathrm{ij}}\right)}{\partial \mathrm{x}_{\mathrm{j}}} \\
& =-\left(\Gamma_{1}+\Gamma_{2}\right)\left(\mathrm{H}_{\mathrm{int} \mathrm{v}}-\mathrm{h}_{\mathrm{lv}}\right)-p \mathrm{u}_{\mathrm{inti}} \frac{\partial \alpha}{\partial \mathrm{x}_{\mathrm{i}}}-\mathrm{u}_{\mathrm{inti}} \mathrm{F}_{\mathrm{Di}}
\end{aligned}
$$

where $u, \rho, \alpha, \Gamma$ and $p$ are velocity, density, liquid volume fraction, mass transfer rate (which will be introduced shortly) and pressure respectively. Additionally, E and $\mathrm{H}$ denote total energy and enthalpy and the interface parameters are defined as:

$$
\begin{aligned}
& u_{\text {inti }}=\frac{\rho_{1} u_{l i} \alpha+\rho_{v} u_{v i}(1-\alpha)}{\alpha \rho_{1}+(1-\alpha) \rho_{v}} \\
& H_{\text {int v }}=h_{v s a t}+u_{\text {int j }} u_{v j}-\frac{1}{2} u_{v j} u_{v j}
\end{aligned}
$$

The drag force between two phases $\left(\mathrm{F}_{\mathrm{D}}\right)$ is computed from a modified Stokes' law as [21]:

$$
\mathrm{F}_{\mathrm{Di}}=4.5 \mathrm{C}_{\mathrm{c}} \frac{\mu_{1} \alpha}{\mathrm{r}^{2}}\left(\mathrm{u}_{\mathrm{vi}}-\mathrm{u}_{\mathrm{li}}\right)
$$


Where $\mathrm{r}$ is the radius of water droplets and $\mathrm{Cc}$ is Cunningham correction factor defined as:

$$
\mathrm{C}_{\mathrm{c}}=1+2 \mathrm{Kn}\left(1.257+0.4 \mathrm{e}^{-1.1 / 2 \mathrm{Kn}}\right)
$$

where $\mathrm{Kn}$ is the Knudsen number. The governing equations for the liquid phase are also defined as follows:

$$
\begin{aligned}
& \frac{\partial\left(\rho_{1} \alpha\right)}{\partial t}+\frac{\partial\left(\rho_{1} \alpha \mathrm{u}_{\mathrm{lj}}\right)}{\partial \mathrm{x}_{\mathrm{j}}}=\Gamma_{1}+\Gamma_{2} \\
& \frac{\partial\left(\rho_{1} \alpha \mathrm{u}_{\mathrm{li}}\right)}{\partial \mathrm{t}}+\frac{\partial\left(\rho_{1} \alpha \mathrm{u}_{\mathrm{lj}} \mathrm{u}_{\mathrm{li}}+\alpha p \delta_{\mathrm{ij}}\right)}{\partial \mathrm{x}_{\mathrm{j}}}-\frac{\partial\left(\alpha \tau_{\mathrm{ij}}\right)}{\partial \mathrm{x}_{\mathrm{j}}}=\left(\Gamma_{1}+\Gamma_{2}\right) \mathrm{u}_{\mathrm{inti}}-\mathrm{F}_{\mathrm{Di}}-\mathrm{p}_{\mathrm{int}} \frac{\partial \alpha}{\partial \mathrm{x}_{\mathrm{i}}} \\
& \frac{\partial\left(\rho_{1} \alpha \mathrm{E}_{1}\right)}{\partial \mathrm{t}}+\frac{\partial\left(\rho_{1} \alpha \mathrm{u}_{\mathrm{lj}} \mathrm{H}_{1}\right)}{\partial \mathrm{x}_{\mathrm{j}}}+\frac{\partial\left(\alpha \mathrm{q}_{\mathrm{lj}}-\alpha \mathrm{u}_{\mathrm{lj}} \tau_{\mathrm{ij}}\right)}{\partial \mathrm{x}_{\mathrm{j}}}=\left(\Gamma_{1}+\Gamma_{2}\right) \mathrm{H}_{\mathrm{intl}}-\mathrm{p}_{\mathrm{int}} \mathrm{u}_{\mathrm{inti}} \frac{\partial \alpha}{\partial \mathrm{x}_{\mathrm{i}}}-\mathrm{u}_{\mathrm{intj}} \mathrm{F}_{\mathrm{D}_{\mathrm{i}}}
\end{aligned}
$$

The effect of gravitational forces is negligible on the flow field within turbine cascades and as the result a single pressure field is assumed for both liquid and gaseous phases in the governing equations 1 and 6 [20, 21]. For modeling the turbulence a modified low-Reynolds k- $\varepsilon$ method and k- $\omega$ SST model are examined. The governing equations for each model are presented as [22, 23]:

\section{$\underline{\text { k-E model: }}$}

$$
\begin{aligned}
& \frac{\partial\left(\alpha_{\mathrm{q}} \rho_{\mathrm{q}} \mathrm{k}_{\mathrm{q}}\right)}{\partial \mathrm{t}}+\frac{\partial\left(\alpha_{\mathrm{q}} \rho_{\mathrm{q}} \mathrm{u}_{\mathrm{q} j} \mathrm{k}_{\mathrm{q}}\right)}{\partial \mathrm{x}_{\mathrm{j}}}=\frac{\partial}{\partial \mathrm{x}_{\mathrm{j}}}\left(\alpha_{\mathrm{q}} \mu_{\mathrm{qk}} \frac{\partial \mathrm{k}_{\mathrm{q}}}{\partial \mathrm{x}_{\mathrm{j}}}\right)+\alpha_{\mathrm{q}} \tau_{\mathrm{ij}} \frac{\partial \mathrm{u}_{\mathrm{qi}}}{\partial \mathrm{x}_{\mathrm{j}}}-\alpha_{\mathrm{q}} \rho_{\mathrm{q}} \varepsilon_{\mathrm{q}} \\
& \frac{\partial\left(\alpha_{\mathrm{q}} \rho_{\mathrm{q}} \varepsilon_{\mathrm{q}}\right)}{\partial \mathrm{t}}+\frac{\partial\left(\alpha_{\mathrm{q}} \rho_{\mathrm{q}} \mathrm{u}_{\mathrm{qj}} \varepsilon_{\mathrm{q}}\right)}{\partial \mathrm{x}_{\mathrm{j}}}=\frac{\partial}{\partial \mathrm{x}_{\mathrm{j}}}\left(\alpha_{\mathrm{q}} \mu_{\mathrm{q} \varepsilon} \frac{\partial \varepsilon_{\mathrm{q}}}{\partial \mathrm{x}_{\mathrm{j}}}\right)+\alpha_{\mathrm{q}} \frac{\varepsilon_{\mathrm{q}}}{\mathrm{k}_{\mathrm{q}}}\left(\mathrm{C}_{\varepsilon 1} \tau_{\mathrm{ij}} \frac{\partial \mathrm{u}_{\mathrm{qi}}}{\partial \mathrm{x}_{\mathrm{j}}}-\mathrm{C}_{\varepsilon 2} \rho_{\mathrm{q}} \varepsilon_{\mathrm{q}}\right)
\end{aligned}
$$




\section{$\underline{\text { k- } \omega \text { SST model: }}$}

$$
\begin{aligned}
& \frac{\partial\left(\alpha_{\mathrm{q}} \rho_{\mathrm{q}} \mathrm{k}_{\mathrm{q}}\right)}{\partial \mathrm{t}}+\frac{\partial\left(\alpha_{\mathrm{q}} \rho_{\mathrm{q}} \mathrm{u}_{\mathrm{q} j} \mathrm{k}_{\mathrm{q}}\right)}{\partial \mathrm{x}_{\mathrm{j}}}=\frac{\partial}{\partial \mathrm{x}_{\mathrm{j}}}\left(\alpha_{\mathrm{q}} \mu_{\mathrm{qk}} \frac{\partial \mathrm{k}_{\mathrm{q}}}{\partial \mathrm{x}_{\mathrm{j}}}\right)+\alpha_{\mathrm{q}} \tau_{\mathrm{ij}} \frac{\partial \mathrm{u}_{\mathrm{qi}}}{\partial \mathrm{x}_{\mathrm{j}}}-\alpha_{\mathrm{q}} \rho_{\mathrm{q}} \varepsilon_{\mathrm{q}} \\
& \frac{\partial}{\partial \mathrm{t}}\left(\alpha_{\mathrm{q}} \rho_{\mathrm{q}} \omega_{\mathrm{q}}\right)+\frac{\partial}{\partial \mathrm{x}_{\mathrm{i}}}\left(\alpha_{\mathrm{q}} \rho_{\mathrm{q}} \omega_{\mathrm{q}} \mathrm{u}_{\mathrm{qi}}\right)=\frac{\partial}{\partial \mathrm{x}_{\mathrm{j}}}\left(\alpha_{\mathrm{q}} \mu_{\mathrm{q} \omega} \frac{\partial \omega_{\mathrm{q}}}{\partial \mathrm{x}_{\mathrm{j}}}\right)+\alpha_{\mathrm{q}} \frac{\omega_{\mathrm{q}}}{\mathrm{k}_{\mathrm{q}}}\left(\mathrm{C}_{\omega 1} \tau_{\mathrm{ij}} \frac{\partial \mathrm{u}_{\mathrm{qi}}}{\partial \mathrm{x}_{\mathrm{j}}}-\mathrm{C}_{\omega 2} \rho_{\mathrm{q}} \omega_{\mathrm{q}}\right)
\end{aligned}
$$

where index q stands for vapor or liquid phase. The extra stress tensor $\tau_{\mathrm{ij}}$ is defined as follows:

$$
\tau_{\mathrm{ij}}=\left(\mu_{\mathrm{L}}+\mu_{\mathrm{T}}\right)\left(\frac{\partial \mathrm{u}_{\mathrm{qi}}}{\partial \mathrm{x}_{\mathrm{j}}}+\frac{\partial \mathrm{u}_{\mathrm{qi}}}{\partial \mathrm{x}_{\mathrm{j}}}-\frac{2}{3} \frac{\partial \mathrm{u}_{\mathrm{qj}}}{\partial \mathrm{x}_{\mathrm{j}}} \delta_{\mathrm{ij}}\right)-\frac{2}{3} \rho_{\mathrm{q}} \mathrm{k}_{\mathrm{q}} \delta_{\mathrm{ij}}
$$

where $\mu_{\mathrm{L}}$ and $\mu_{\mathrm{T}}$ are laminar and turbulent viscosities, respectively [24, 25]. Further details on the constants of these models can be found in Refs. [22, 23].

In order to calculate the vapor properties at different thermodynamic states the real gas model embedded in the IAPWS-IF97 formulation [26] is utilized. Subsequently, the equation of state for the vapor phase is given by:

$$
\frac{p_{v}}{R T_{v} \rho_{v}}=A\left(T_{v}\right)+B\left(T_{v}\right) \rho_{v}
$$

where $\mathrm{A}\left(\mathrm{T}_{\mathrm{v}}\right)$ and $\mathrm{B}\left(\mathrm{T}_{\mathrm{v}}\right)$ are defined as follows:

$$
\begin{aligned}
& \mathrm{A}\left(\mathrm{T}_{\mathrm{v}}\right)=\mathrm{a}_{0}+\mathrm{a}_{1} \mathrm{~T}_{\mathrm{v}}+\mathrm{a}_{2} \mathrm{~T}_{\mathrm{v}}{ }^{2} \\
& \mathrm{~B}\left(\mathrm{~T}_{\mathrm{v}}\right)=\mathrm{b}_{0}+\mathrm{b}_{1} \mathrm{~T}_{\mathrm{v}}+\mathrm{b}_{2} \mathrm{~T}_{\mathrm{v}}{ }^{2}
\end{aligned}
$$

The temperature dependent constants of $a_{i}$ and $b_{i}(i=0,1,2)$ in Eqs. 11 are obtained from the data available in Ref. [26]. The liquid water thermodynamic properties (viscosity, density, enthalpy and speed of sound) are also determined byIAPWS-IF97 formulations. 


\section{Non-equilibrium Condensation Model}

The modeling of non-equilibrium condensation frequently starts with the classical nucleation theory proposed by Deich et al. [27]. The radius of critical droplet $\left(\mathrm{r}^{*}\right)$ which must be attained in order to form a stable nucleus from supersaturated vapor according to the real equation of state is defined as [21]:

$$
r^{*}=\frac{2 \sigma\left(T_{1}\right)}{\rho_{1}\left[f\left(p_{v}\right)-f\left(p_{\text {sat }}\right)\right]-\left(p_{v}-p_{\text {sat }}\right)}
$$

where:

$$
f(p)=\frac{b}{2} \ln p+c-\frac{b}{2} \ln \left(\frac{1+\frac{c}{b}}{1-\frac{c}{b}}\right)
$$

$\mathrm{b}=\mathrm{A}(\mathrm{T}) \mathrm{RT}$

$$
\mathrm{c}=\left[(\mathrm{A}(\mathrm{T}) \mathrm{RT})^{2}+4 \mathrm{pB}(\mathrm{T}) \mathrm{RT}\right]^{0.5}
$$

The nucleation rate of droplet is also described by Eq. 14 [28]:

$$
\mathrm{J}=\frac{\mathrm{q}_{\mathrm{c}}}{1+\theta} \frac{\rho_{\mathrm{v}}{ }^{2}}{\rho_{\mathrm{l}}} \sqrt{\frac{2 \sigma}{\pi \mathrm{M}^{3}}} \exp \left(-\frac{4 \pi \mathrm{r}^{* 2} \sigma}{3 \mathrm{~K}_{\mathrm{b}} \mathrm{T}_{\mathrm{v}}}\right)
$$

where $\mathrm{M}$ is the mass of one water molecule, $\mathrm{K}_{\mathrm{b}}$ is the Boltzmann constant, $\mathrm{q}_{\mathrm{c}}$ is the condensation coefficient and is generally taken as unity, $\sigma$ is the liquid surface tension and $\theta$ is a nonisothermal correction factor which is given by the following relation [28]:

$$
\theta=\frac{2(\gamma-1)}{(\gamma+1)}\left(\frac{\mathrm{h}_{\mathrm{lv}}}{\mathrm{RT}_{\mathrm{v}}}\right)\left(\frac{\mathrm{h}_{\mathrm{lv}}}{\mathrm{RT}_{\mathrm{v}}}-0.5\right)
$$

where $\mathrm{h}_{\mathrm{lv}}$ is the latent heat of evaporation at pressure $\mathrm{p}$. The growth rate of nucleated droplets is expressed as follows [28]: 
$\frac{\mathrm{dr}}{\mathrm{dt}}=\frac{1}{\mathrm{~h}_{\mathrm{lv}} \rho_{1}} \frac{\frac{\lambda_{\mathrm{v}}}{\mathrm{r}}}{\frac{1}{1+1.5 \mathrm{Kn}}+3.78(1-\mathrm{v}) \frac{\mathrm{Kn}}{\operatorname{Pr}}}\left(\mathrm{T}_{1}-\mathrm{T}_{\mathrm{v}}\right)$

The factor (1-v) is a semi-empirical correction introduced by [28]:

$v=\frac{\mathrm{RT}_{\mathrm{sat}}(\mathrm{p})}{\mathrm{h}_{\mathrm{lv}}}\left(\psi(\mathrm{p})-0.5-\frac{1}{2} \frac{\gamma+1}{2(\gamma-1)} \frac{\mathrm{RT}_{\mathrm{sat}}(\mathrm{p})}{\mathrm{h}_{\mathrm{lv}}}\right) ; \psi(\mathrm{p})=3.25\left[1-\tanh \left(\frac{\mathrm{p}}{10^{4}}-2\right)\right]$

Finally, the radius of droplets is acquired from the moments method proposed by Hill [4]:

$$
\begin{array}{ll}
\mathrm{k}=0 & \frac{\partial\left(\mu_{0}\right)}{\partial \mathrm{t}}+\frac{\partial\left(\mu_{0} \mathrm{u}_{\mathrm{lj}}\right)}{\partial \mathrm{x}_{\mathrm{j}}}=\mathrm{J} \\
\mathrm{k}=1 & \frac{\partial\left(\mu_{1}\right)}{\partial \mathrm{t}}+\frac{\partial\left(\mu_{1} \mathrm{u}_{\mathrm{lj}}\right)}{\partial \mathrm{x}_{\mathrm{j}}}=\mathrm{r}^{*} \mathrm{~J}+\frac{\mathrm{dr}}{\mathrm{dt}} \mu_{0} \\
\mathrm{k}=2 & \frac{\partial\left(\mu_{2}\right)}{\partial \mathrm{t}}+\frac{\partial\left(\mu_{2} \mathrm{u}_{\mathrm{lj}}\right)}{\partial \mathrm{x}_{\mathrm{j}}}=\mathrm{r}^{* 2} \mathrm{~J}+2 \frac{\mathrm{dr}}{\mathrm{dt}} \mu_{1}
\end{array}
$$

In Eqs. 18, $\mu_{\mathrm{k}}$ is the k-th moment of droplets radius distribution with the definition of

$$
\mu_{\mathrm{k}}=\int_{0}^{\infty} \mathrm{r}^{\mathrm{k}} \mathrm{fdr}, \mathrm{k}=0,1,2, \ldots ; \mathrm{f}(\mathrm{r}, \mathrm{x}, \mathrm{t})=\frac{\partial \mathrm{n}(\mathrm{r}, \mathrm{x}, \mathrm{t})}{\partial \mathrm{r}}
$$

Where $\mathrm{n}$ is the number of liquid droplet per unit mass of the mixture. The average droplet radius is then calculated as:

$$
r=\sqrt{\frac{\mu_{2}}{\mu_{0}}}
$$

According to the condensation model adopted here (Eqs. 12-18), the phase change is represented by two mass sources: 


$$
\begin{aligned}
& \Gamma_{1}=\frac{4}{3} \pi \rho_{1} \mathrm{r}^{* 3} \mathrm{~J} \\
& \Gamma_{2}=4 \pi \rho_{\mathrm{l}} \rho_{\mathrm{m}} \mathrm{nr}^{2} \frac{\mathrm{dr}}{\mathrm{dt}}
\end{aligned}
$$

where $\Gamma_{1}$ is the mass source of critical droplets created due to the nucleation process, and $\Gamma_{2}$ is the mass condensation rate of all droplets per unit volume of the two-phase mixture. These mass sources will be directly submitted to the Eq. 1 and Eq. 6 to give a closure to our set of governing equations.

\section{Numerical Method}

\subsection{Problem Description}

Shape optimization of a nozzle/blade cascade in its most general form could be regarded as a minimization problem with the following mathematical formulation,

$$
\min _{\underline{x}} f[\underline{U}(\underline{x}), \underline{x}] \text { subjected to } g_{i}(\underline{x}) \leq 0 ; i=1,2, \ldots, m
$$

where

- $\mathrm{f}$ is the objective function which should be selected carefully from relevant two-phase flow properties.

- $\underline{\mathrm{x}}$ is the vector of geometric entities which parameterized the profile of nozzle/turbine cascade.

- $\underline{\mathrm{U}}(\underline{\mathrm{x}})$ is the vector of flow parameters including pressure and velocity fields.

- $\mathrm{g}_{\mathrm{i}}(\underline{\mathrm{x}}) \leq 0$ is a non-equality constraint that should be upheld constantly through optimization process. 


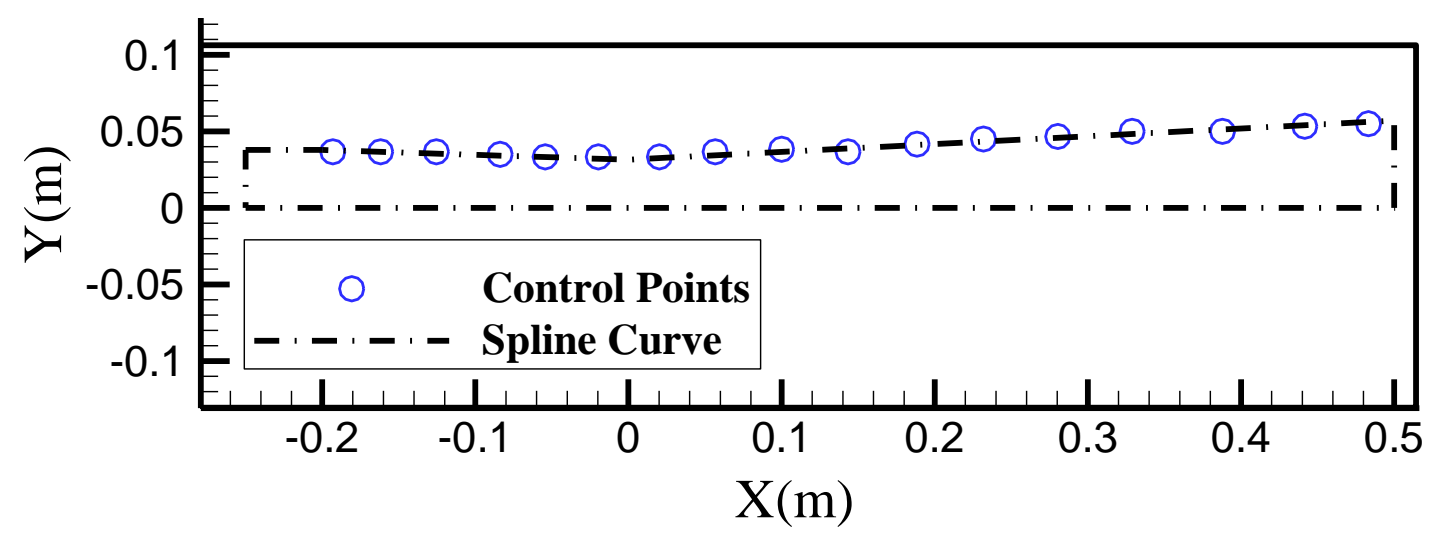

(a) nozzle

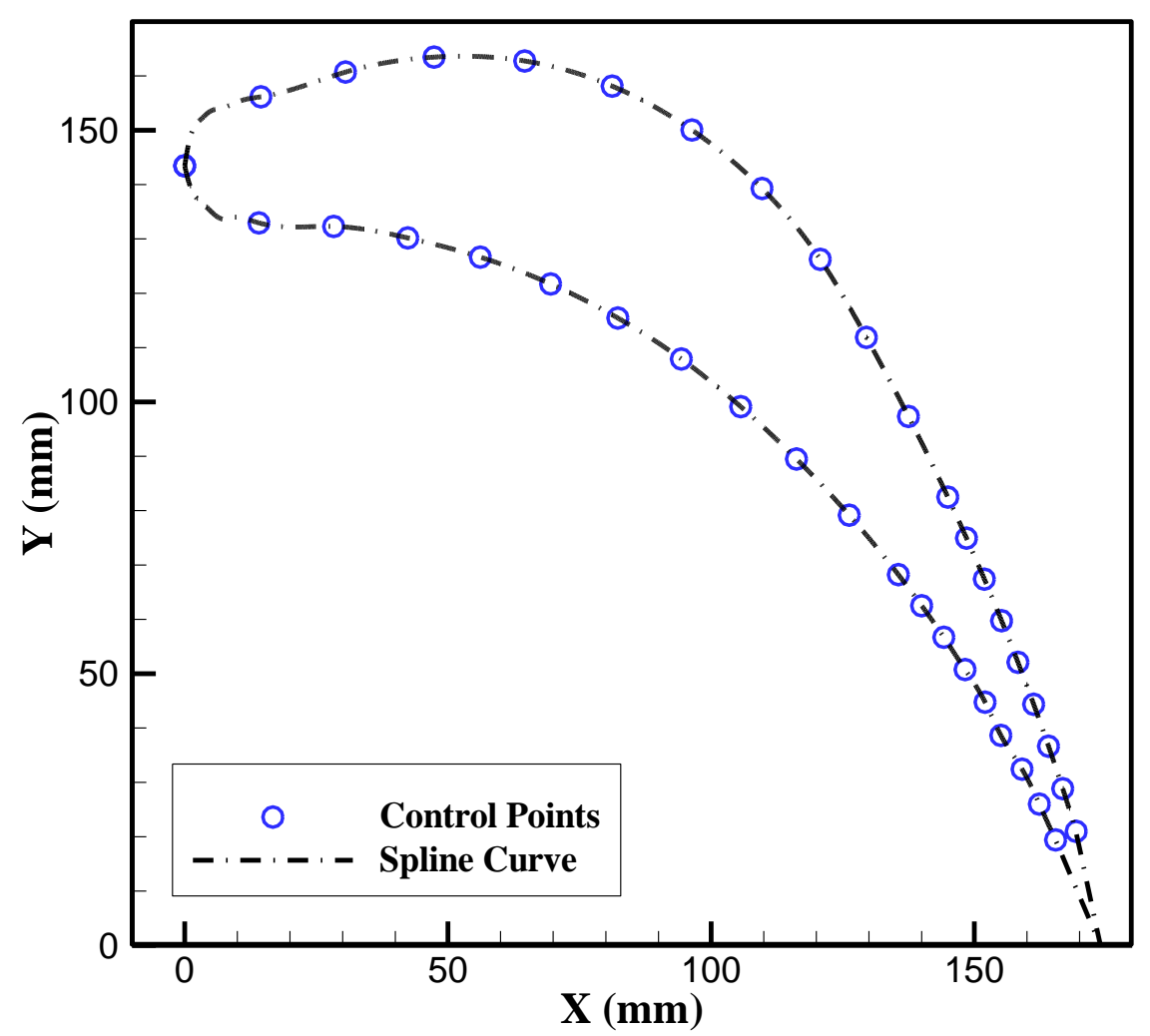

(b) blade

Figure 1. Parametrizing of the profiles with cubic spline curves(a) nozzle and (b) turbine blade

For each objective function evaluation, the nozzle/blade profile has to be constructed based on geometric parameters $(\underline{\mathrm{x}})$ and a corresponding numerical mesh needs to be generated. On this 
numerical mesh, the governing equations of Eq. 1 should be solved to acquire 10 main unknown flow parameters $(\underline{\mathrm{U}}(\underline{\mathrm{x}}))$ including velocity vector, pressure field, turbulence dissipation rate, kinetic energy and volume fraction. When the flow parameters are obtained, the objective function is calculated from its mathematical definition. To parameterize the nozzle and turbine blade profiles, $\mathrm{N}$ discrete control points (the vector $\underline{\mathrm{x}}=\left[\mathrm{x}_{\mathrm{cp}, \mathrm{l}} \mathrm{y}_{\mathrm{cp}, 1} \ldots \mathrm{x}_{\mathrm{cp}, \mathrm{i}} \mathrm{y}_{\mathrm{cp}, \mathrm{i}} \ldots \mathrm{x}_{\mathrm{cp}, \mathrm{N}} \mathrm{y}_{\mathrm{cp}, \mathrm{N}}\right]$ contains the coordinates of these control points in respect to a specific frame of reference) are chosen on the solid surfaces and the profiles are approximated with a set of cubic spline curves between consecutive pairs of these control points (see Figs.1 (a) and (b)). New profiles could be easily obtained by varying the coordinates of each control point. Based on this approach, $2 \mathrm{~N}$ unknown geometric variables exist in the optimization problem that their values at the optimal solution of the problem should be calculated employing a proper optimization algorithm.

\subsection{Optimization Algorithm}

The optimization problem introduced earlier in sec 4.1 is solved using the well-known Genetic algorithms (GA) as a reliable global optimizer. GA is a gradient-free optimizer which benefits from probabilistic transition to search within numerous solution candidates (which are collectively called a generation) for the optimal solution of a particular optimization problem [29-31]. In this study Non-Dominated Sorting GA (NSGA II) [31] is utilized for the optimization as its suitable performance for shape optimization has been approved by many researchers [32, 33]. The optimization algorithm can be summarized as:

Step 0: Building a surrogate model of real shape optimization problem: To overcome the exorbitant computational cost of function evaluations of GA in the shape optimization problem, it is advised to develop a surrogate function from a design of experiment (DOE) approach [32]. 
In this method, for a relatively high but reasonably limited number of design candidates which are evenly distributed in the design space, a numerical mesh is generated and the value of twophase objective function is evaluated from the numerical solution of the governing equations. From this set of data, an approximate surrogate model is built which gives the value of objective function and subsequently it will be used for function evaluation in GA.

Step1: Creation of first generation of candidates: In this study, the first population is created randomly within the design space. The population of each generation is fixed at 60 .

Step2: For each generation, the algorithm evaluates all candidates using surrogate model.

Step3: After the evaluation process, the best candidates of each generation are selected as parents to generate potentially better solutions using Roulette wheel search model which ranks every individual based on its fitness value [29-30]. Producing new individuals (offspring) is carried out by linear crossover operator and 10 percent of off springs are mutated to produced better solution candidates. Elitism is also employed to keep the best fitted individuals (between 2-4 individuals) of each generation from being degraded by GA operators.

Step4: Now a new generation is created and the loop is carried out repeatedly until the maximum number of generations is completed.

Step 5: For the case of Multi-objective optimization the Pareto-ranking [29] is adapted which is able to identify solutions which satisfy the objectives at an acceptable level without being dominated by any other solutions. Details on Pareto-ranking can be found in [30]. The Pareto front is obtained for each pair of objectives.

\subsection{Flow Solver}

To numerically solve the governing equations of 1 through 21 , an in-house CFD code was developed based on finite volume approach. A coupled, implicit and second order discretization 
scheme is used to improve the accuracy of the solution. The criterion of $10^{-5}$ is set for the convergence of the obtained solution. As it was stated before, the following assumptions are considered for the numerical simulation:

1. The two phases have the same average pressure and a single pressure field is used for both liquid and gas phases.

2. The flow field is assumed to be unsteady and turbulent.

3. The properties vapor and liquid phase are calculated based on the IAPWS-IF97 formulations.

4. A non-equilibrium condensation model based on classical nucleation and growth theory was adopted.

As the inlet boundary condition the total pressure is set for both nozzle and turbine cascade. Moreover, the no-slip condition is considered at the walls of the nozzle and on the surface of turbine blade. The flow field is considered to be stationary and the computational domain is filled by only the vapor at the beginning of each simulation (initial condition).

\section{Results and discussion}

In the following section, subsequent to the verification of our numerical code, numerical results concerning the shape optimization of a 3D nozzle and a 2D turbine blade cascade in the presence of non-equilibrium condensation is presented. The shape optimization procedure is aimed to reduce thermodynamic and aerodynamic losses (which are collectively called wetness loss) caused by the occurrence of non-equilibrium condensation. These losses are commonly associated with the production of entropy and their extents could be assessed by the computation of overall entropy generation rate through the flow passage. To achieve the goal of wetness loss 
reduction, the shape of a $3 \mathrm{D}$ nozzle or $2 \mathrm{D}$ turbine blades needs to be modified to suppress the phase change phenomenon within the flow domain. One is able to weaken the non-equilibrium condensation via diminishing following quantities,

(1) Liquid mass fraction $\left(\mathrm{x}_{1}\right)$

(2) Nucleation rate $(\mathrm{J})$

(3) Droplet radius (r)

Each one of the preceding properties or their combination (as a multi-objective merit function) could be regarded as the objective function for the shape optimization process. However, the efficacy of these objective functions regarding the reduction of wetness loss (or the overall entropy generation rate) should be further examined in order to delineate the best suited objective function for the problem in hand. The corresponding task is undertaken as well in the proceeding subsections and objective functions considered in the present work are summarized in table 1.

Table 1. Summary of objective functions

\begin{tabular}{|cccc|}
\hline Case & Objective Function & Symbol & Mathematical Expression \\
\hline $\mathbf{C}_{1}$ & Liquid mass fraction & $\mathrm{x}_{1}$ & $\mathrm{x}_{1}=\frac{\dot{\mathrm{m}}_{1}}{\dot{\mathrm{m}}_{1}+\dot{\mathrm{m}}_{\mathrm{v}}}$ \\
\hline $\mathbf{C}_{2}$ & Nucleation rate & $\mathrm{J}$ & $\mathrm{J}=\frac{\mathrm{q}_{\mathrm{c}}}{1+\theta} \frac{\rho_{\mathrm{v}} \rho_{1}}{\sqrt{\frac{2 \sigma}{\pi \mathrm{M}^{3}}}} \exp \left(-\frac{4 \pi \mathrm{r}^{* 2} \sigma}{3 \mathrm{~K}_{\mathrm{b}} \mathrm{T}_{\mathrm{v}}}\right)$ \\
\hline $\mathbf{C}_{\mathbf{3}}$ & Droplet radius & $\mathrm{r}$ & $\mathrm{r}=\sqrt{\frac{\mu_{2}}{\mu_{0}}}$ \\
\hline $\mathbf{C}_{\mathbf{4}}$ & Multi-objective & $\left(\mathrm{x}_{1}, \mathrm{~J}, \mathrm{r}\right)$ & -- \\
\hline
\end{tabular}

\subsection{Code verification and base profiles}

To verify the capability of our numerical code in resolving prominent characteristics of twophase flows with spontaneous nucleation, two test cases are considered here. Firstly, the well- 
known Moore's "nozzle A" [34] is adopted and its 3D geometry is depicted in Fig. 2. The total pressure and temperature at the nozzle inlet are fixed at $\mathrm{P}_{0}=25 \mathrm{kPa}$ and $\mathrm{T}_{0}=354.6 \mathrm{~K}$. A quadrilateral Cartesian structured numerical mesh was generated with the size of $120 \times 10 \times 5$

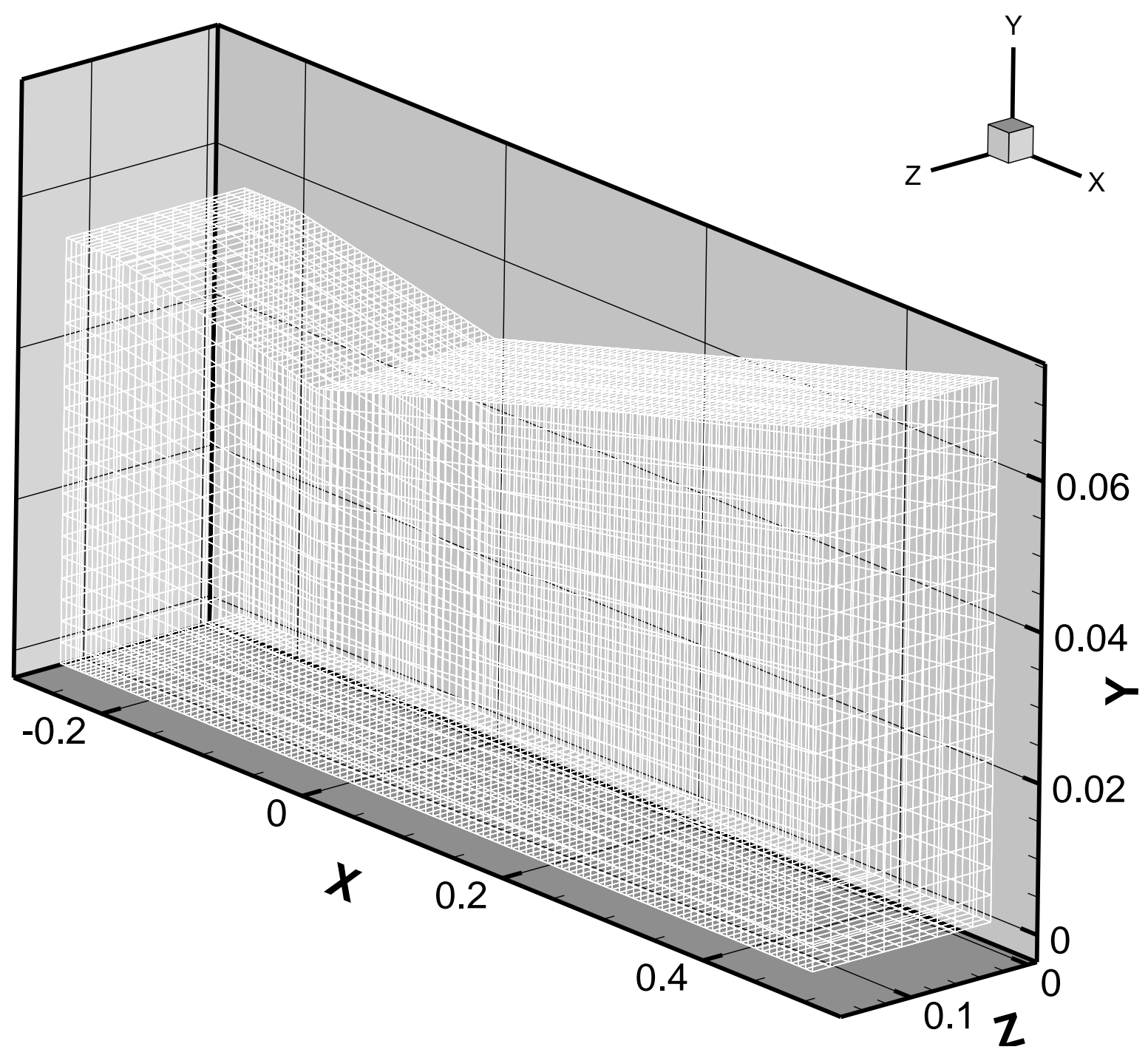

Figure 2. Nozzle geometry

Figure 3. Effect of the grid resolution on the pressure along the axis of the nozzle

$\left(\mathrm{N}_{\mathrm{x}} \times \mathrm{N}_{\mathrm{y}} \times \mathrm{N}_{\mathrm{z}}\right)$. The optimal size of numerical mesh was selected based on a mesh dependency study presented in Fig. 3 . 


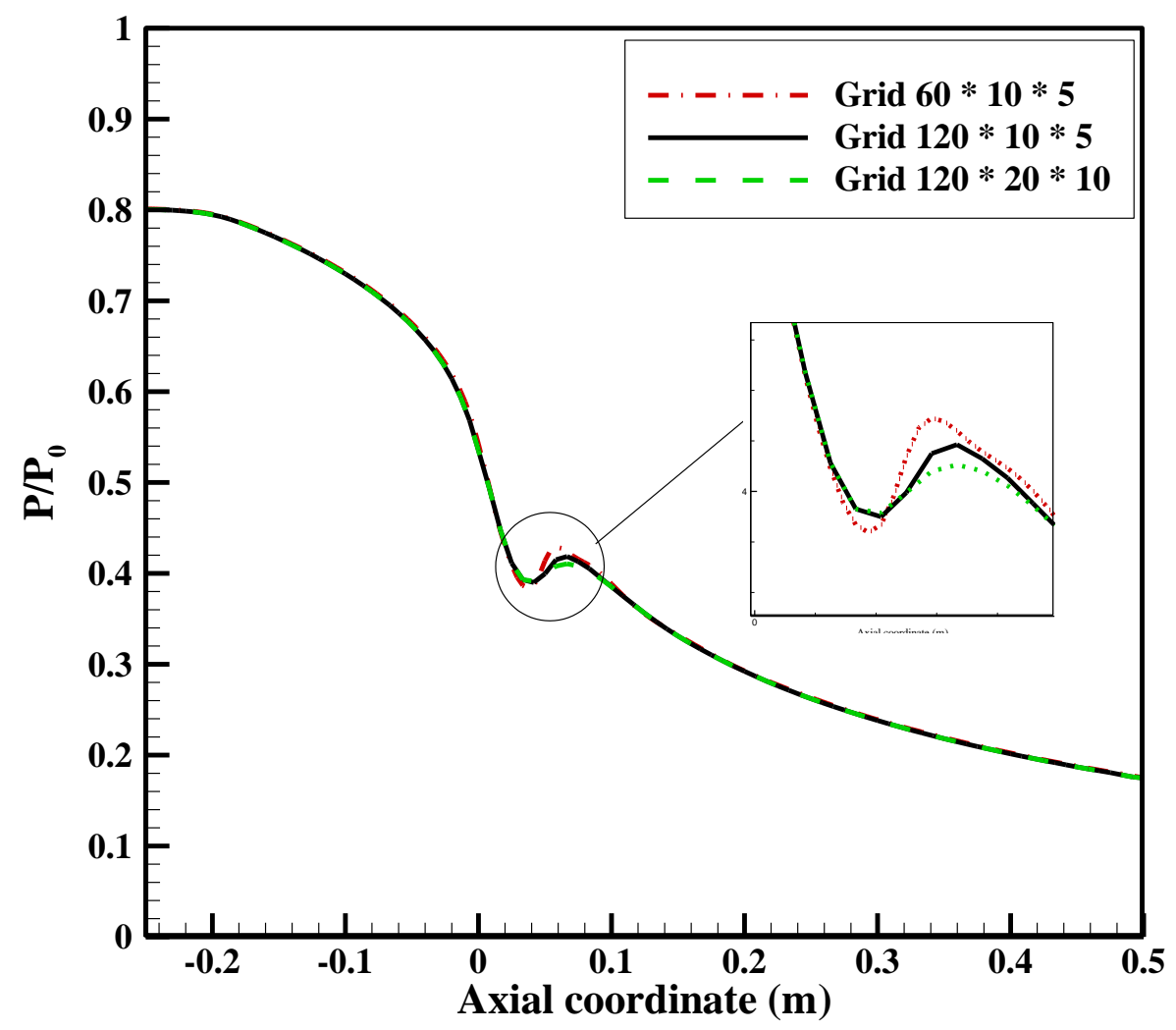

Figure 3. Effect of the grid resolution on the pressure along the axis of the nozzle

In Fig. 4, static pressure and mean droplet radius obtained from numerical simulation are compared with the experimental data provided in [34]. The comparison of the computed static pressure distribution along the nozzle centerline with its corresponding experimental measurements shows that our CFD code is well capable of capturing the location and intensity of non-equilibrium condensation and produces reliable results. As it can be seen, the static pressure decreases along the nozzle and experiences a sudden increase when the non-equilibrium condensation happens; a phenomenon which is known as "condensation shock" and it is mainly attributed to the release of significant latent heat during condensation which elevates vapor temperature and subsequently its static pressure. Additionally, the predicted droplet radius distribution along the nozzle is in a reasonable agreement with the experimental data. 


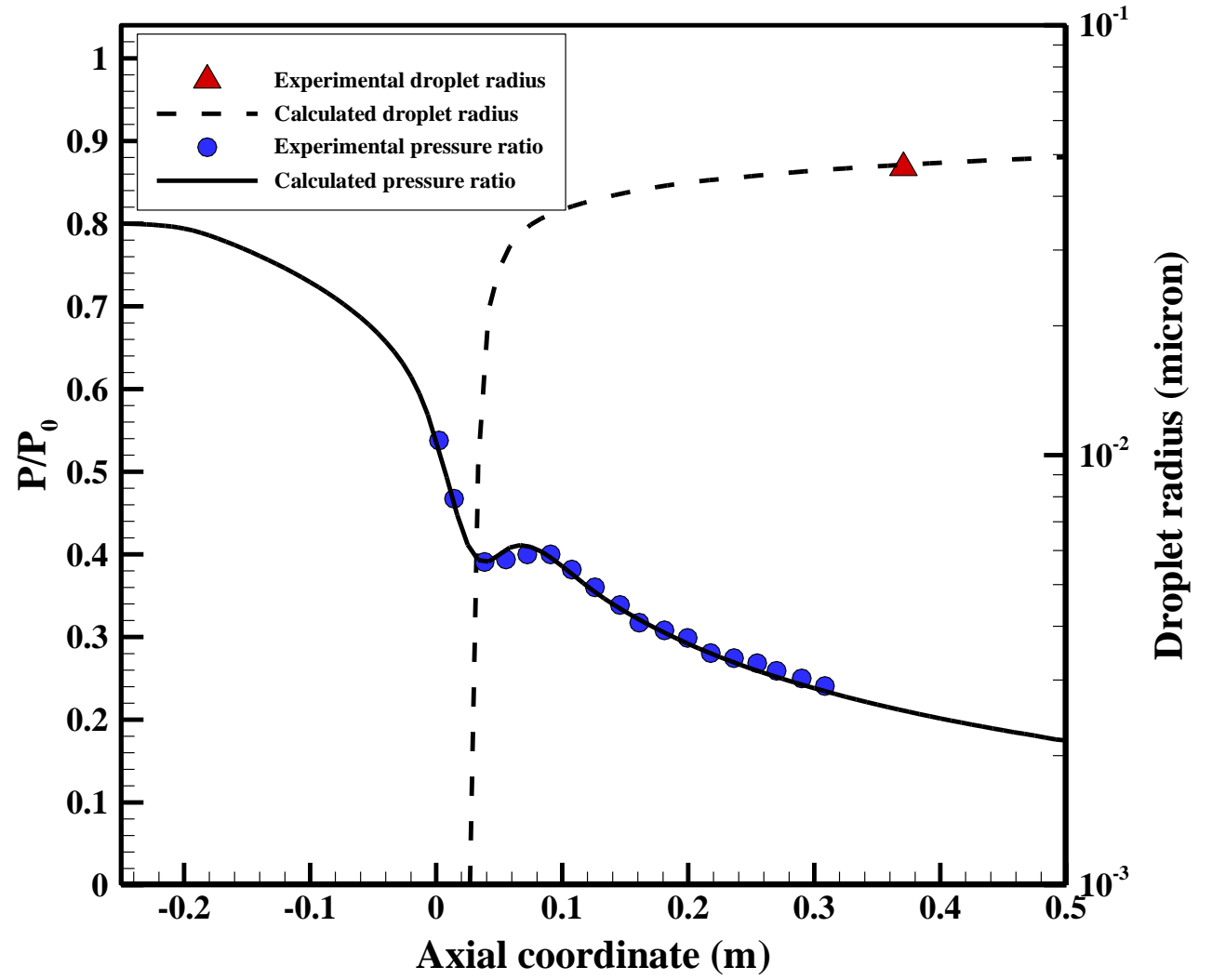

Figure 4. Comparison of the present calculation results with the experimental data [34]

As the second case for the validation of our CFD code, the steam turbine blade cascade of Dykas et al. [15] is considered. The cascade is designed to operate under the condition of $\mathrm{P}_{0}=89 \mathrm{kPa}$ and $\mathrm{T}_{0}=373.15 \mathrm{~K}$ at its flow inlet. Fig. 5 depicts the computational domain and the multi-block numerical mesh that is generated for numerical simulation. The numerical grid is consists of 43480 quadrilateral computational cells with its size is chosen through a detailed grid size study. 


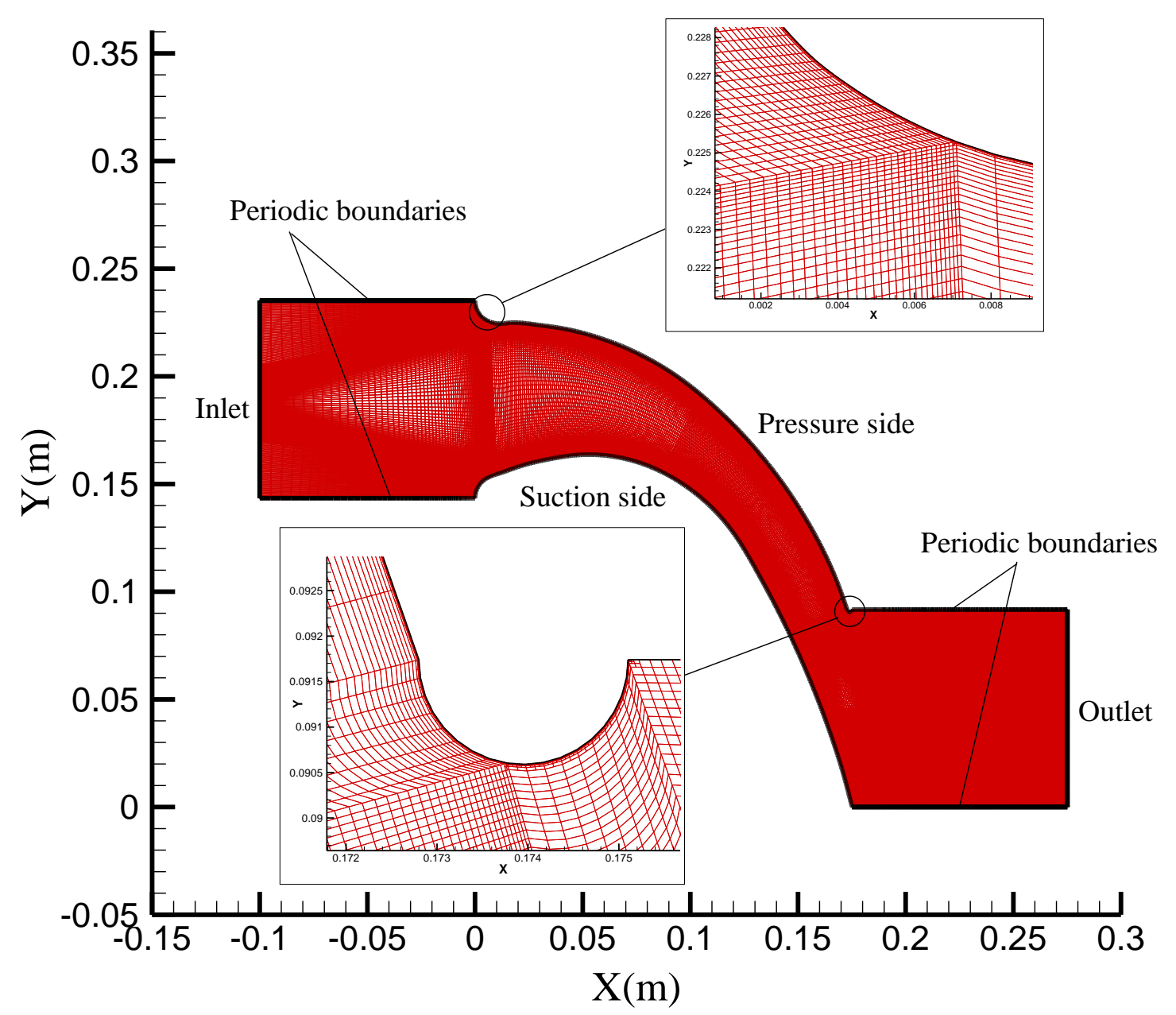

Figure 5. Multi-block grid for the blade cascade and relevant boundary conditions

Fig. 6 shows the distributions of static pressure at the pressure and suction sides of turbine blade. As it can be seen, our numerical results coincide with the experimental data which further corroborates the accuracy and reliability of our numerical approach. Moreover, the employed non-equilibrium condensation model can accurately predict the position of condensation shock (sudden jump in static pressure at the suction side of the blade) inside the turbine cascade. 


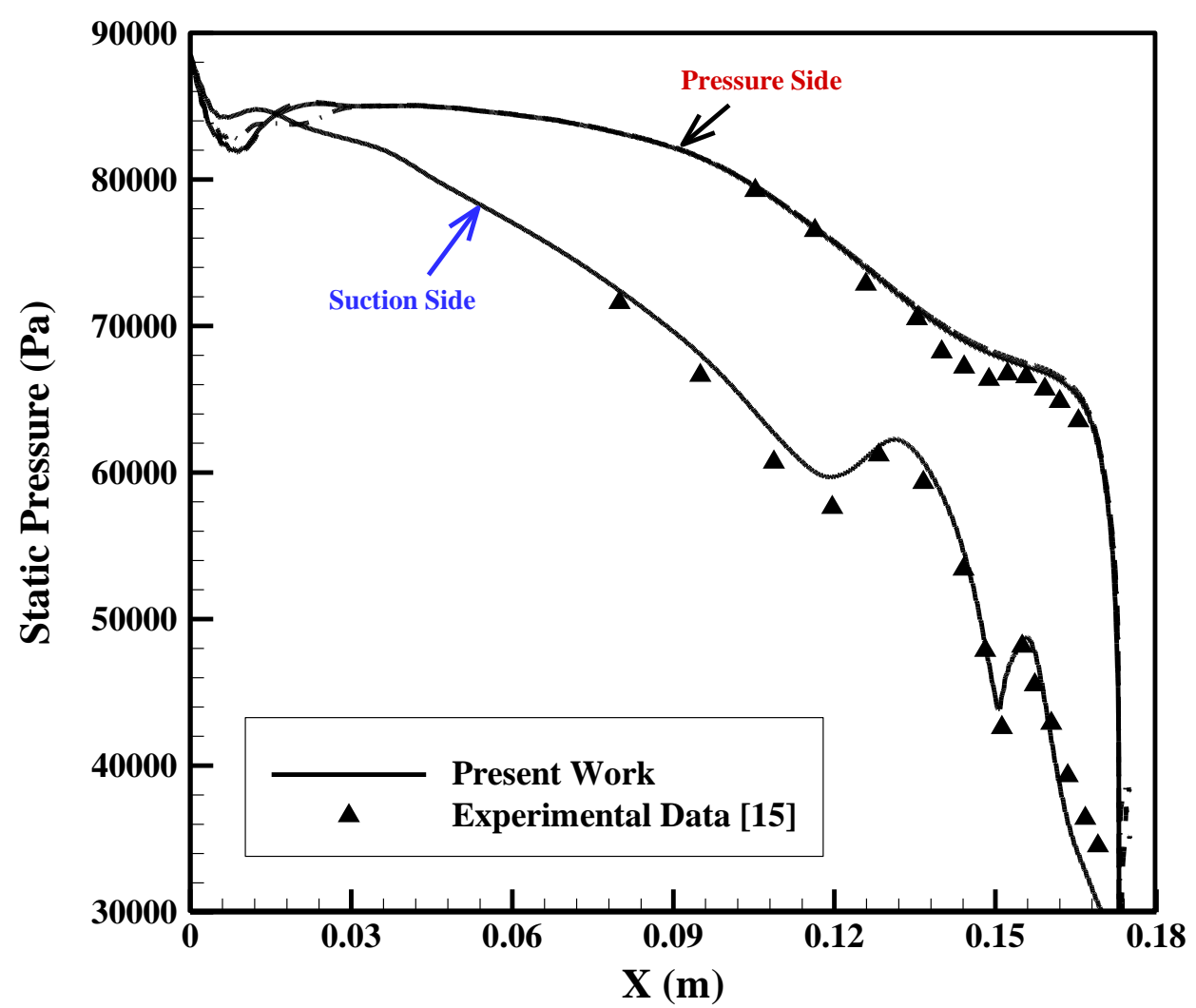

Figure 6. Static pressure distribution over turbine blade

Being done with the verification of our CFD code, it should be mentioned that in this work the Moore's "Nozzle A" [34] and the turbine blade cascade of Dykas et al. [15] are selected as the base profiles for the shape optimization process.

\subsection{The Effect of Turbulence Modeling}

Selection of a proper turbulence model is a crucial part of a successful simulation of high-speed flows including the transonic and supersonic flows through nozzles and blade cascades. Therefore, in this section, we are intended to assess the performance of two widely used two equation turbulence models of "Realizable $k-\varepsilon$ " and "k- $\omega$ SST" in predicting the wet steam transonic flows within nozzles and turbine blade cascade. To do so, the same grid sizes are 


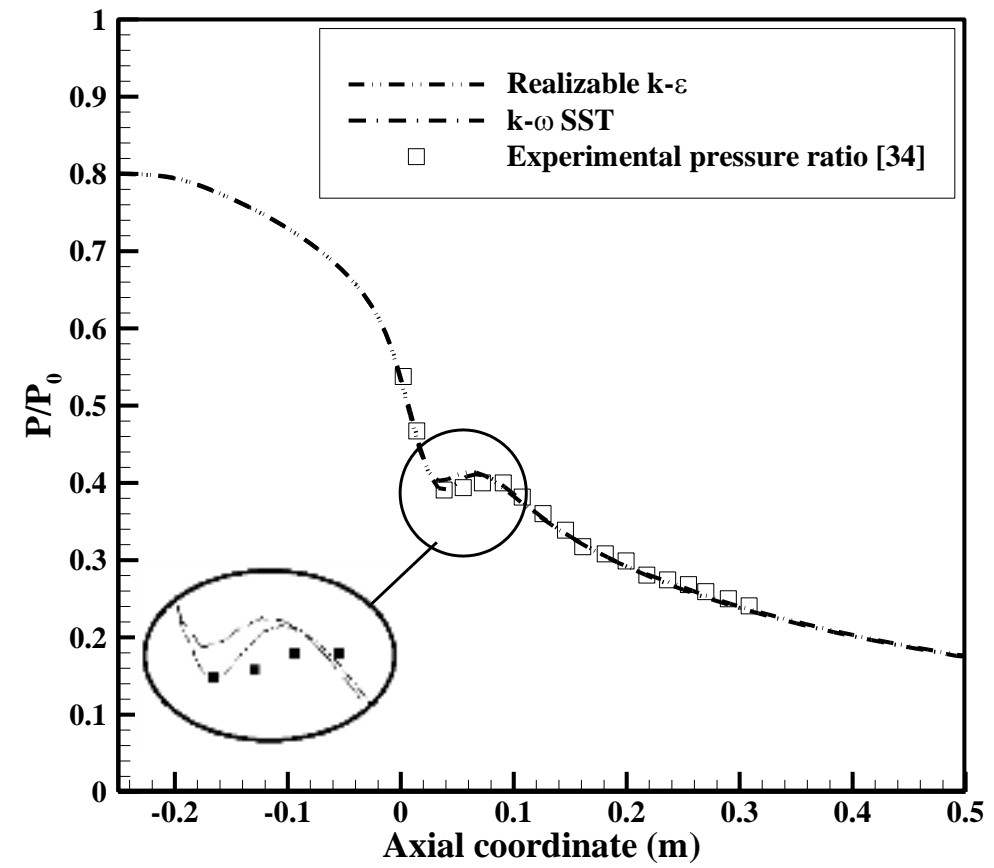

(a)

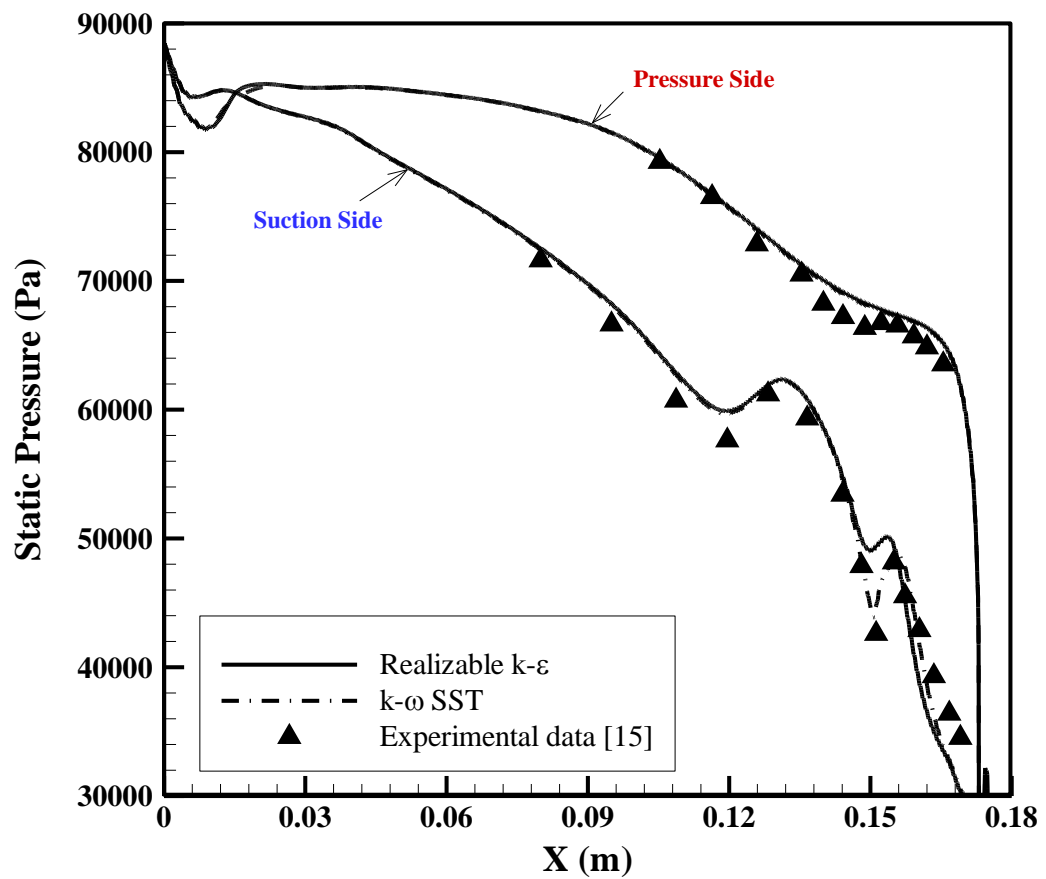

(b)

Figure 7. Effect of turbulence modelling on the pressure distribution: (a) Nozzle, (b) Turbine blade cascade

applied for both turbulence models and the grid resolutions are carefully monitored for $\mathrm{y}^{+}$to reach the value unity at the solid boundaries of the computational domain. 
The pressure distribution along the centerline of Moore's "Nozzle A" and at the blade surface of Dykas's turbine cascade are computed using two aforementioned turbulence models. A comparison is drawn between numerical data and available experimental measurements in Fig. 7. As it can be seen, for both geometries, k- $\omega$ SST model is able to predict the static pressure

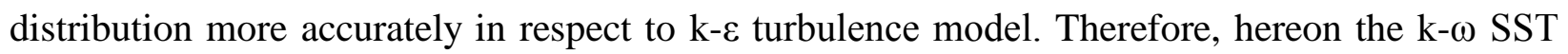
model is used for all the simulation presented in the manuscript.

\subsection{Shape Optimization of Moore's "Nozzle A"}

In this section, to reduce the so-called wetness loss prompted by non-equilibrium condensation in wet steam flows through Moore's "Nozzle A", the wall profile of this nozzle was modified via conducting a shape optimization using three objective functions introduced earlier in table 1 . As three constrains to the optimization problem, it is considered that the inlet, outlet and throat area of the nozzle remain unchanged after each nozzle profile modification. The obtained optimal nozzle profiles are illustrated in Fig. 8. As it can be seen, optimization mostly altered the nozzle profile near its flow outlet and in this region optimized profiles are noticeably deviate from the linear base profile. 


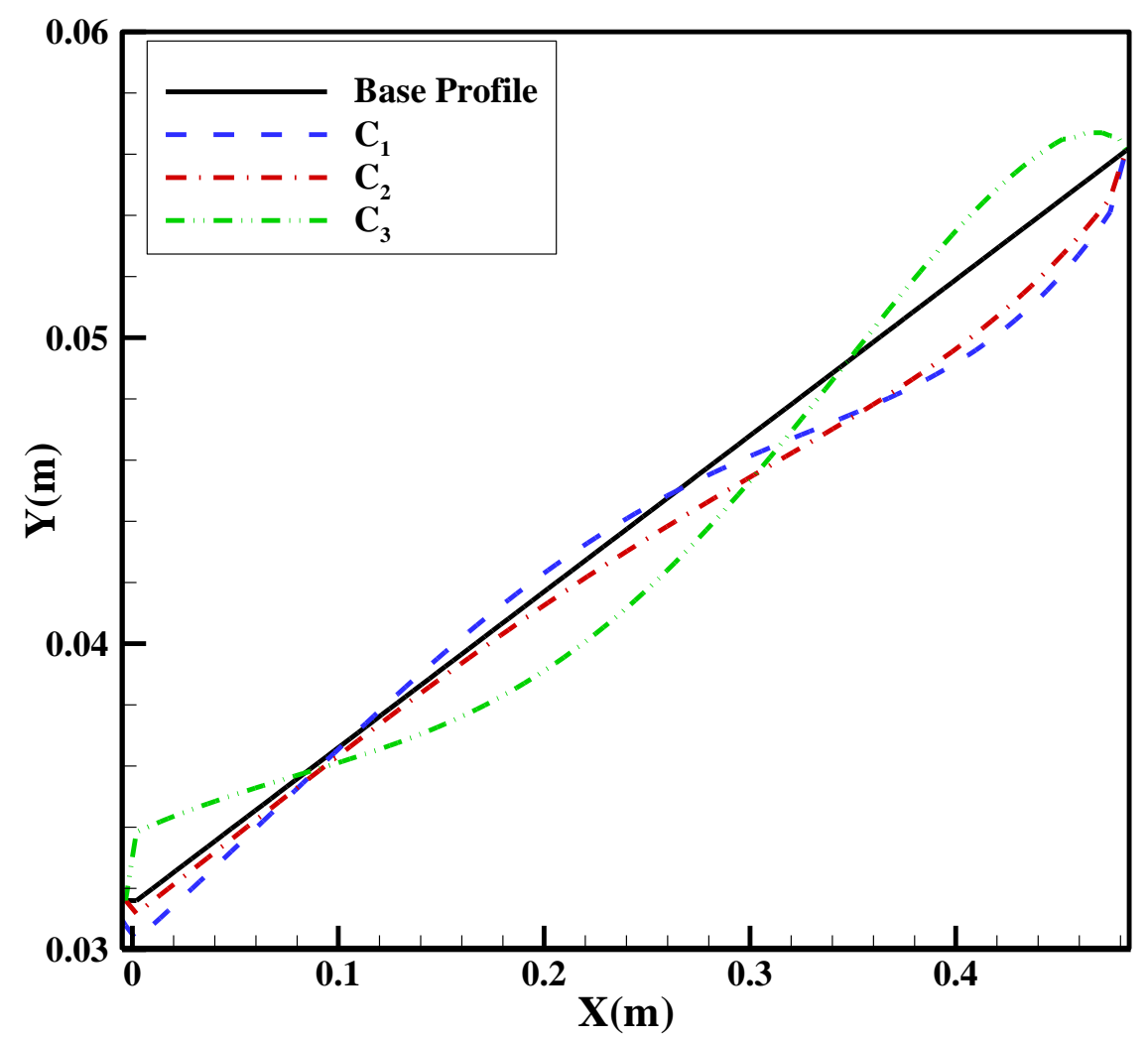

Figure 8. Comparison between the base and optimal nozzle profile

The success of each shape optimization scenario for wet steam flows could be judged base on two important parameters (in respect to the base case of the optimization process),

(1) Reduction in Entropy Generation (REG): which correlates the reduction in thermodynamic and aerodynamic losses caused by nucleating flow.

(2) Reduction in Maximum Droplet Diameter (RMDD): which correlates the reduction in erosion loss cause by wet steam.

These two parameters are presented in table 2 for all the optimization cases considered here. 
Table 2. RMDD and REG within the nozzle for optimized profiles

\begin{tabular}{|cccccc|}
\hline Case & $\begin{array}{c}\text { Total pressure } \\
\text { change }(\mathbf{P a})\end{array}$ & $\begin{array}{c}\text { Maximum droplet } \\
\text { diameter }(\boldsymbol{\mu m})\end{array}$ & RDR $(\boldsymbol{\%})$ & $\begin{array}{c}\text { Entropy generation } \\
(\mathbf{J} / \mathbf{k g} . \mathbf{K})\end{array}$ & $\begin{array}{c}\text { REG } \\
(\boldsymbol{\%})\end{array}$ \\
\hline Base profile & 1904 & 0.0515 & -- & 13.3 & -- \\
\hline $\mathbf{C}_{\mathbf{1}}$ & 1182 & 0.0378 & 26 & 4.1 & 69 \\
\hline $\mathbf{C}_{\mathbf{2}}$ & 911 & 0.0436 & 15 & 2.5 & 81 \\
\hline $\mathbf{C}_{\mathbf{3}}$ & 936 & 0.0208 & 59 & 3.1 & 76 \\
\hline
\end{tabular}

According to table 2, for all of optimized profiles, entropy production and droplet radius decrease relative to the base profile. However, the lowest entropy generation rate corresponds to the case $\mathrm{C}_{2}$ (the case with nucleation rate as the objective function) for which a significant $81 \%$ REG is reported. At the same time, as it is expected the highest RMDD of $59 \%$ is achieved for $\mathrm{C}_{3}$ (the case with droplet radius as the objective function) for which the second largest REG is reported. This conclusion is justified in Fig. 9 that shows the distributions of static pressure along the axis of the nozzle. As it can be seen, the optimization of nozzle profile elevates the steam pressure across the divergent section of the nozzle and postpones the occurrence of spontaneous nucleation and weakens its strength. As the result, no noticeable condensation shock is observed in the modified pressure profiles. Moreover, the highest pressure level is observed for the case $\mathrm{C}_{2}$ which results in sever supersession of condensation and highest value of REG. 


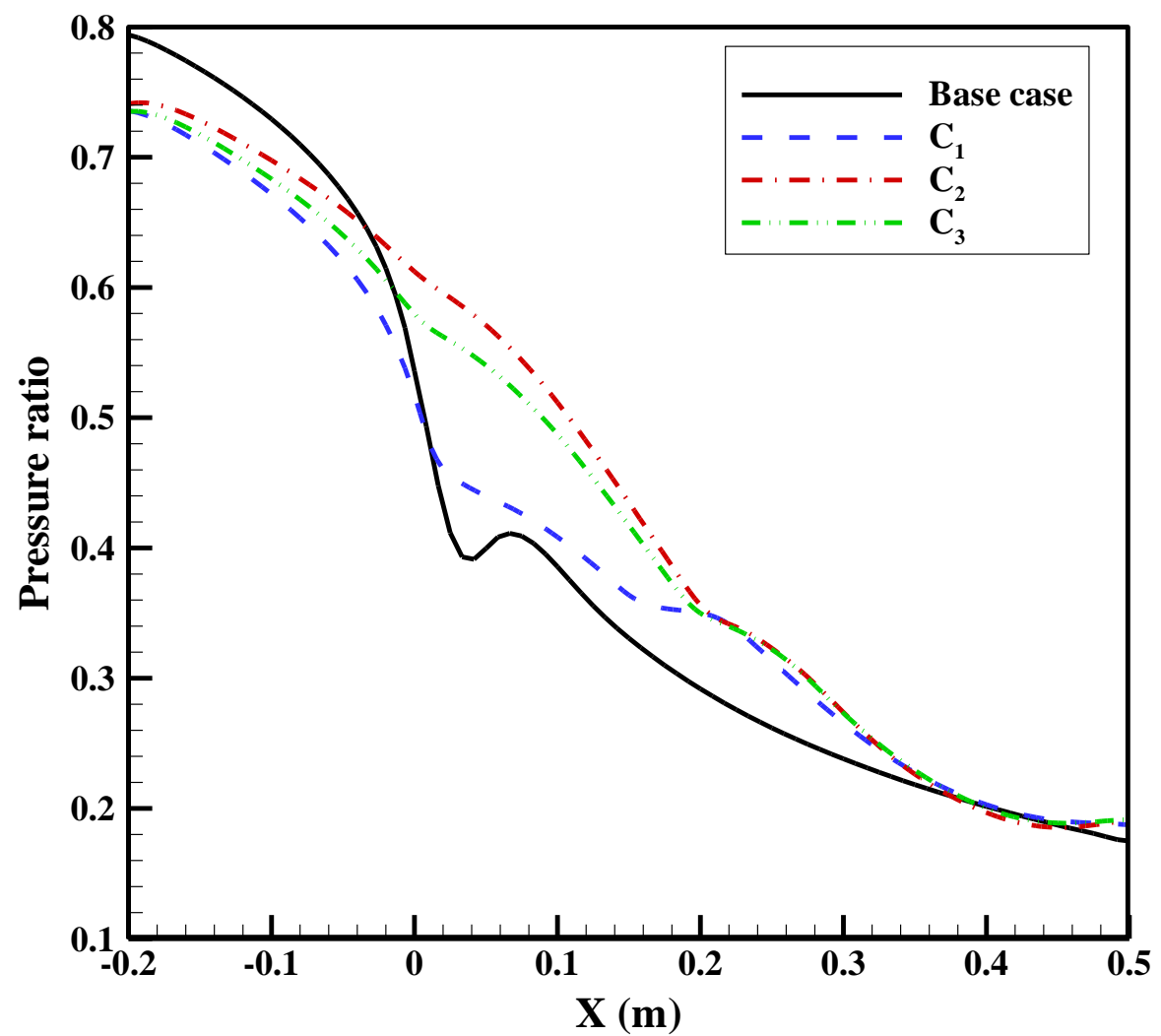

Figure 9. Pressure distribution along the axis of the nozzle for optimized profiles

To further investigate the effect of shape optimization of Moore's "Nozzle A" on the nucleating flow field passing through the nozzle, in Fig. 10, various characteristics of the wet steam flow are depicted for all of the optimized cases. According to Fig. 10a, profile optimization delays the onset of nucleation (while no noticeable changes are observed in the maximum nucleation rate) and significantly reduces the number of water droplets in the vicinity of nozzle throat (see Fig. 10c). Therefore, for all the optimized nozzle profiles, the liquid mass fraction is reduced in comparison to the base profile throughout the nozzle. Naturally, the lowest liquid mass fraction belongs to case $\mathrm{C}_{1}$; however the liquid mass fraction at the nozzle outlet is approximately identical for all the optimized cases. Moreover, for optimized profiles of $\mathrm{C}_{2}$ and $\mathrm{C}_{3}$, the relaxation of water droplet radius is limited as well (see Fig. 10d). The optimization is most 
successful for case $\mathrm{C}_{2}$ when droplet growth is restricted as much as possible and nucleation sites are shifted toward the nozzle outlet as far as possible. This observation reveals that "nucleation rate" is the dominant factor for decreasing the wetness loss in steam condensing flows inside nozzles.
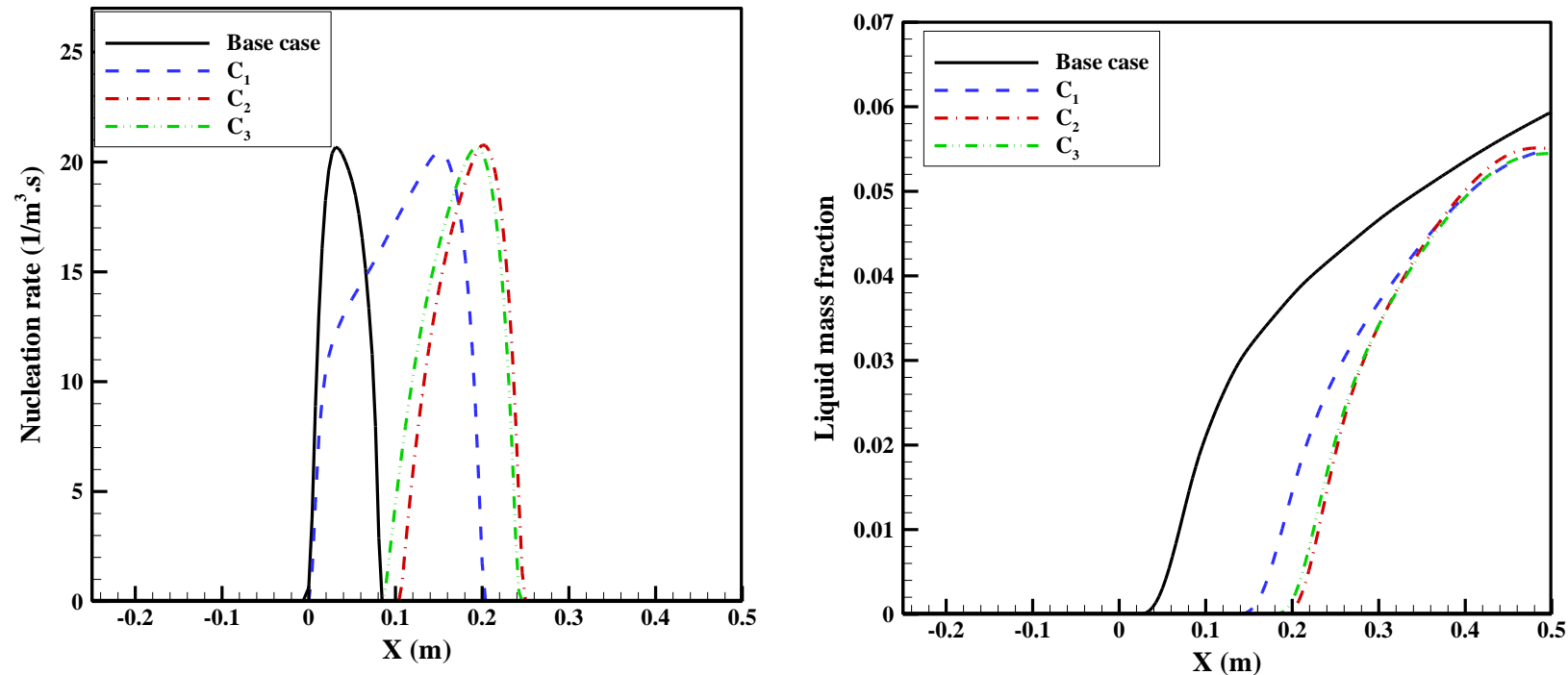

(a)

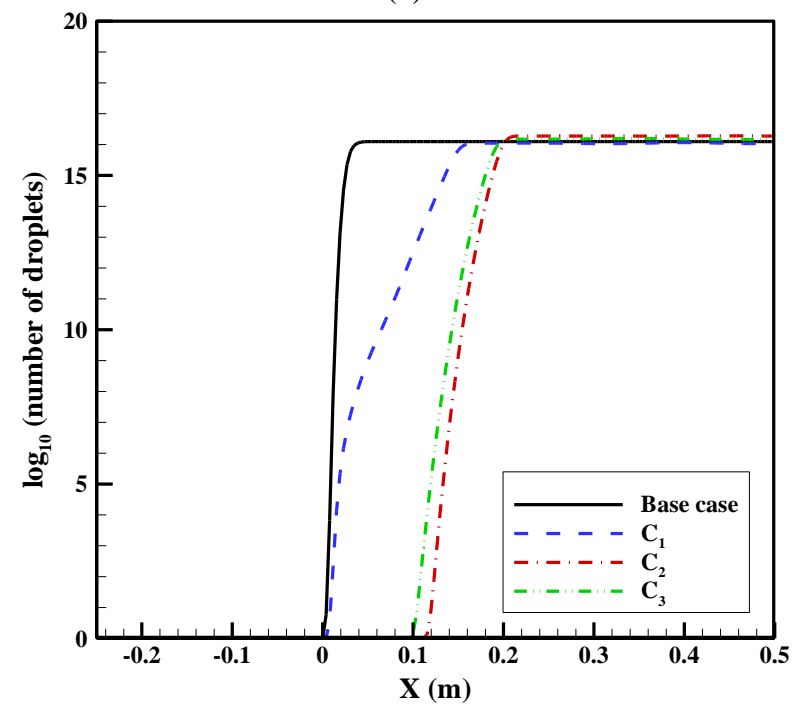

(c)

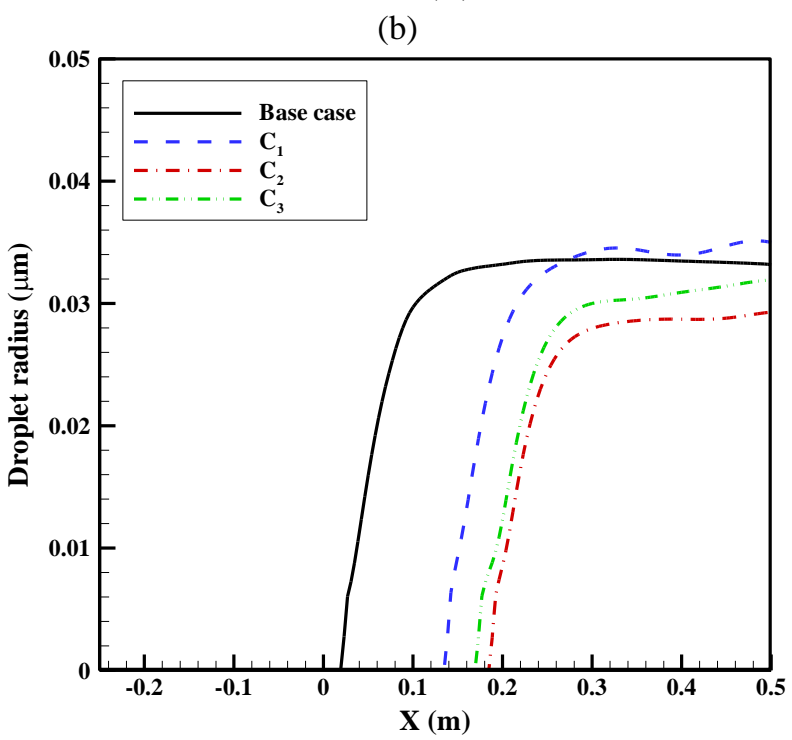

(d)

Figure 10. Effect of shape optimization on the characteristics of wet steam flow: (a) Nucleation rate, (b) Liquid mass fraction, (c) Number of Droplets, (d) Maximum droplet radius 


\subsection{Shape Optimization of Dykas's Turbine Blade Cascade}

As our main case of shape optimization, the blade cascade of a steam turbine stator experimentally studied by Dykas et al [15] is considered. The cascade is a part of small steam condensing power plant located at the Silesian University of Technology. Similar to the case of Moore's "nozzle A", four different objective functions are adopted as it was presented in table 1. Moreover, the areas of inlet and outlet cross sections of the blade cascade are fixed during the optimization process. Fig. 11 illustrates the base and all of optimized blade profiles.

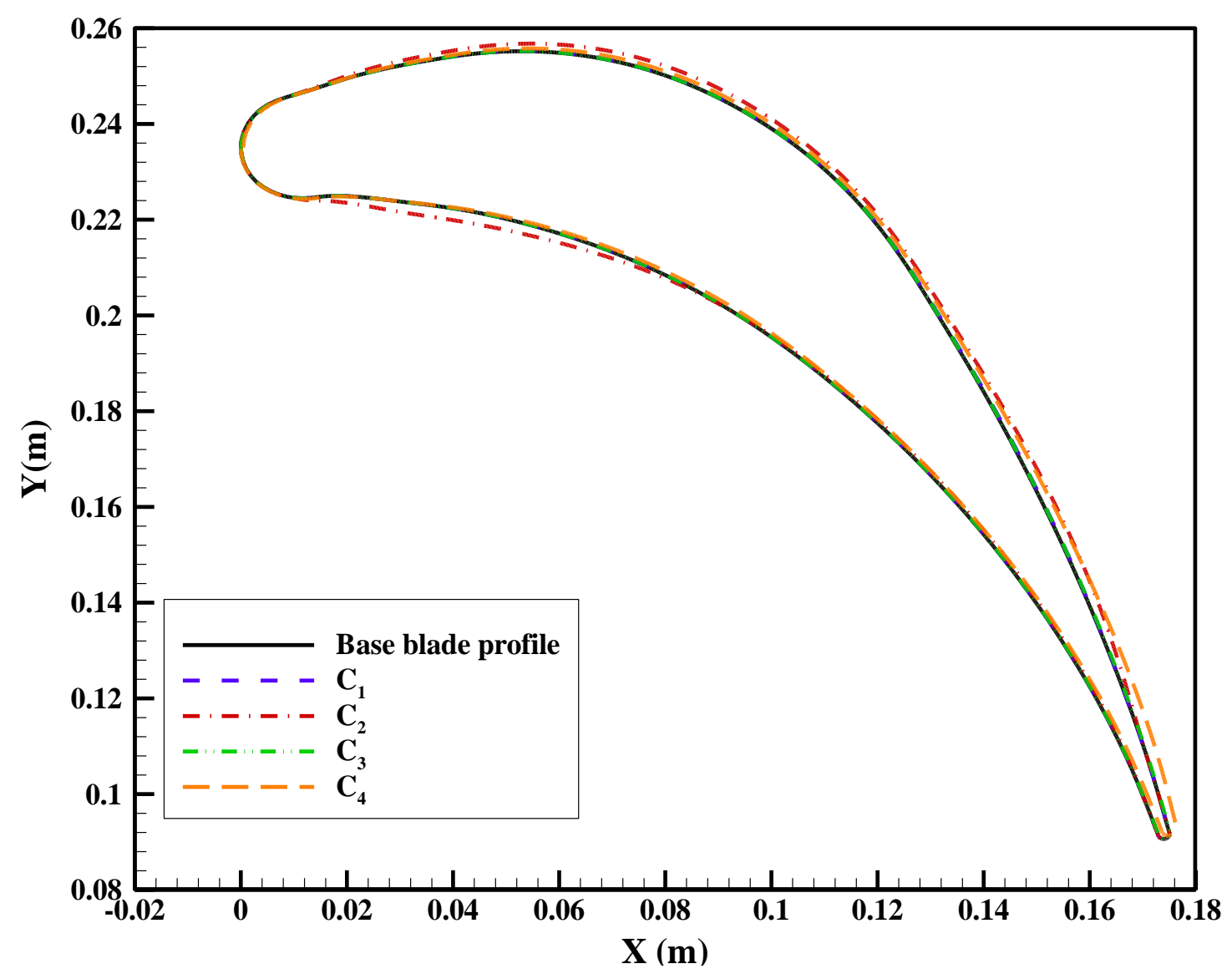

Figure 11. Optimized blade profiles with respect to different objective functions 
The main goal of optimizing the blade profile is to reduce wetness loss within the blade cascade. Therefore, the merit of each optimization attempt is measured using REG, RMDD (previously introduced in section 5.3) and isentropic efficiency. These three prominent parameters are given in table 3 in which the efficiency of turbine blade cascade is calculated as follows, $\eta_{\mathrm{s}}=\frac{\mathrm{h}_{\text {in }}-\mathrm{h}_{\text {out }}}{\mathrm{h}_{\mathrm{in}}-\mathrm{h}_{\mathrm{out}, \mathrm{s}}}$

where $\mathrm{s}$ is the isentropic condition and $\mathrm{h}$ is the enthalpy of wet steam.

Table 3. Summary of results regarding optimization of turbine blade profile

\begin{tabular}{|cccccc|}
\hline Case & Base Profile & $\mathbf{C}_{\mathbf{1}}$ & $\mathbf{C}_{\mathbf{2}}$ & $\mathbf{C}_{\mathbf{3}}$ & $\mathbf{C}_{\mathbf{4}}$ \\
\hline Total pressure change (Pa) & 2477 & 3246 & 3036 & 3368 & 3092 \\
\hline Entropy generation (J/kg.K) & 19.7 & 15.0 & 16.0 & 13.0 & 16.0 \\
\hline REG (\%) & -- & 23.8 & 18.7 & 34 & 18.7 \\
\hline RMDD (\%) & -- & 5.9 & 5.8 & 15 & 5.9 \\
\hline Blade isentropic efficiency (\%) & 89.9 & 91.5 & 91.3 & 92 & 91.3 \\
\hline $\mathbf{F}_{\text {lift }} / \mathbf{F}_{\text {drag }}$ & 0.469 & 0.471 & 0.470 & 0.470 & 0.470 \\
\hline Maximum nucleation rate (1/kg.m $\mathbf{3})$ & $10^{23.22}$ & $10^{23.1}$ & $10^{23.11}$ & $10^{23.06}$ & $10^{23.1}$ \\
\hline
\end{tabular}

According to table 3 after each shape optimization attempt, slight alteration of the blade profile at its trailing edge (where the nucleation and non-equilibrium condensation occurs) results in a notable decrease in overall entropy generation rate and a desirable raise in the blade cascade isentropic efficiency. The maximum increase in the blade cascade efficiency (or equivalently maximum REG) belongs to case $\mathrm{C}_{3}$ (with droplet radius as the target function for minimization) with $2.1 \%$ increase in $\eta_{s}$ (or 34\% REG). Additionally, maximum RMDD is also achieved for the 
case $\mathrm{C}_{3}$. Therefore, the most suited objective function for shape optimization of Dykas's turbine blade cascade is the maximum droplet radius. The second best case is case $\mathrm{C}_{1}$ in which liquid mass fraction is considered as the objective function. As a final note, it worth mentioning that the ratio of lift to drag forces are essentiality the same for all the optimized cases; because the optimization procedure presented here is mainly concerned with the thermodynamic loss in the non-equilibrium condensation rather than aerodynamics loss of the primary phase.

The elevation of isentropic efficiency for optimized blade profiles could be easily justified noting that the wetness loss caused by condensation is proportional to the strength of the condensation shock. The condensation shock itself is very sensitive to the expansion rate within the cascade which is mainly controlled by the blade profile. As it can be seen in Fig. 12 (where the static pressure distribution along the suction and pressure sides of turbine blade is depicted), the strength of the condensation shock for the optimized profiles diminishes considerably due to reduced expansion rate which results in lower wetness losses and subsequently higher efficiencies. 


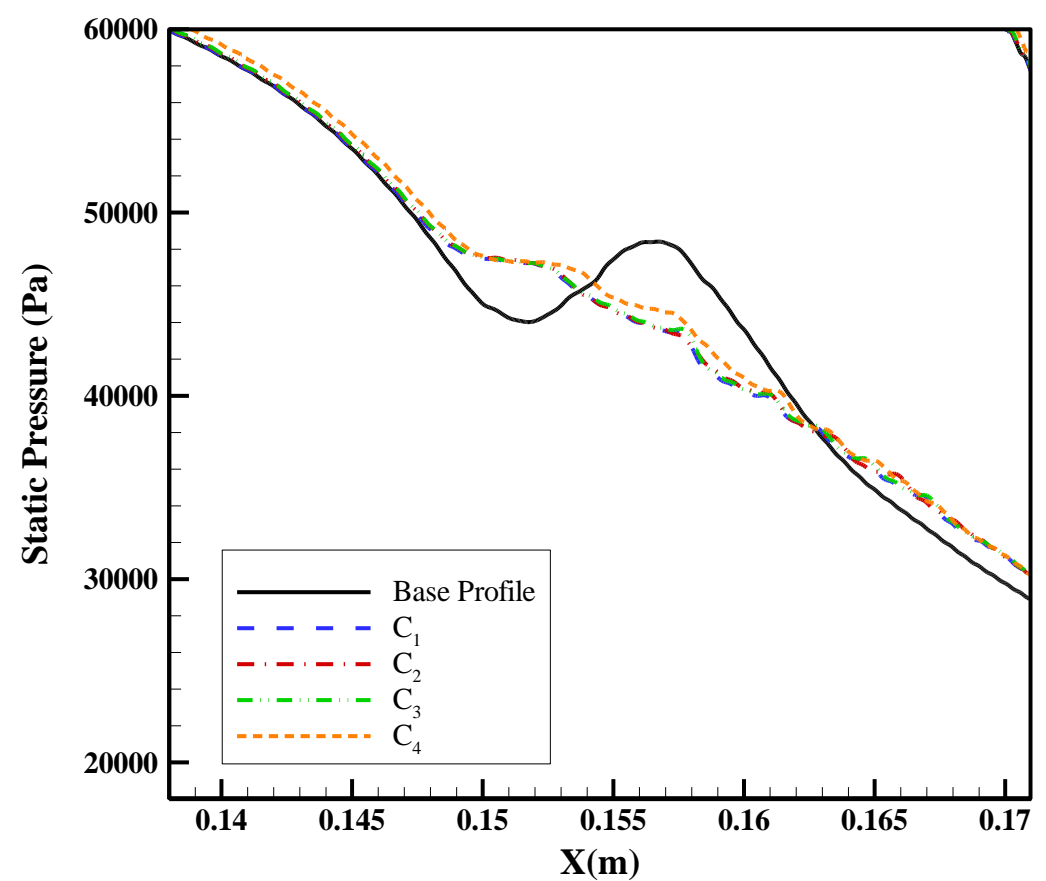

(b)

Figure 12. Distribution of static pressure at the blade surfaces with optimized profiles: (a) Overall view, (b) Zoomed view

To gain a better insight into the nucleating flow within a turbine blade cascade and the effect of blade optimization on the wet steam flow properties, In Fig. 13, contours of Mach number are illustrated for all the optimization scenarios examined in this work. For all the cases, the occurrence of a shock wave at the trailing edge of the blade is predicted. This oblique shock wave is previously reported in the experimental image of Schieren [2] who studied the condensing flow inside a turbine cascade. The shape optimization slightly decreases the Mach number especially around the trailing edge of turbine blade and weakness the shock wave. 

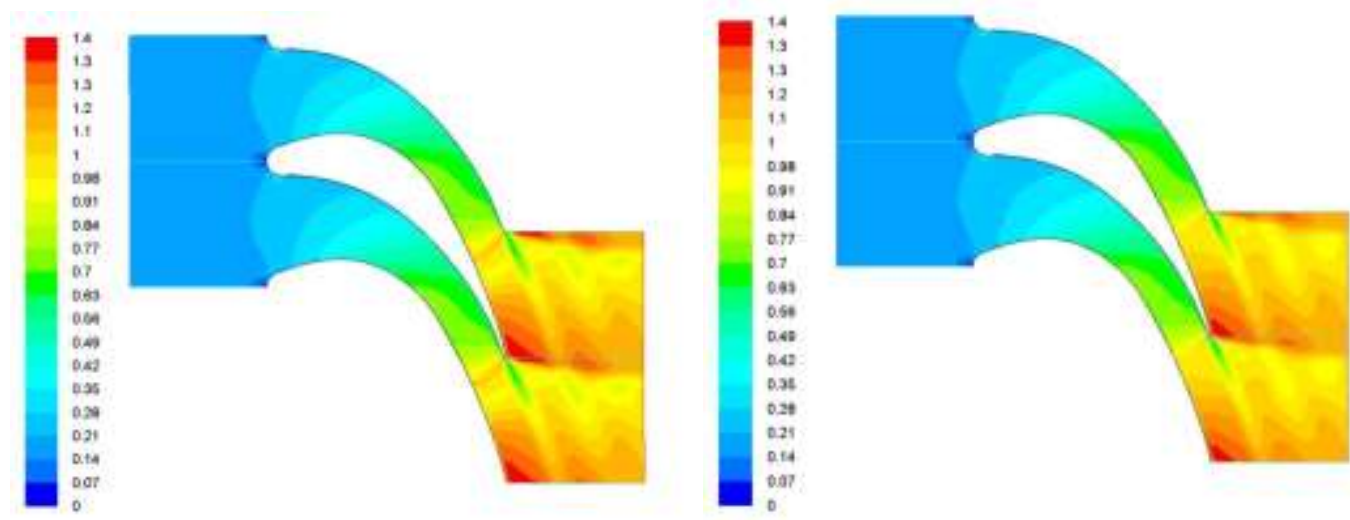

(a)

(b)
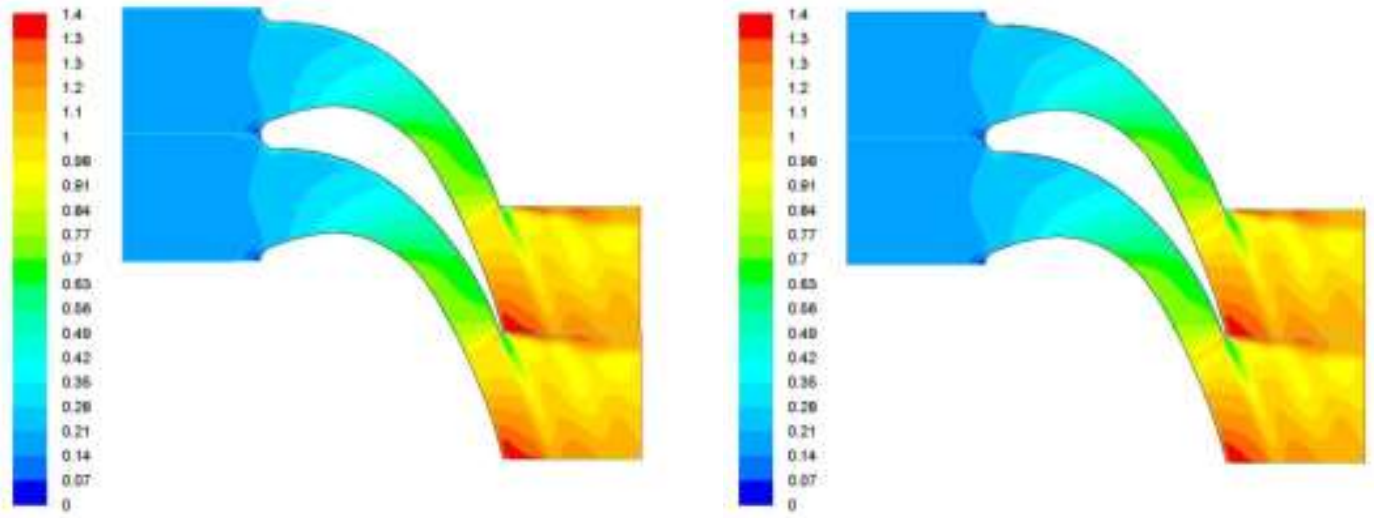

(c)

(d)

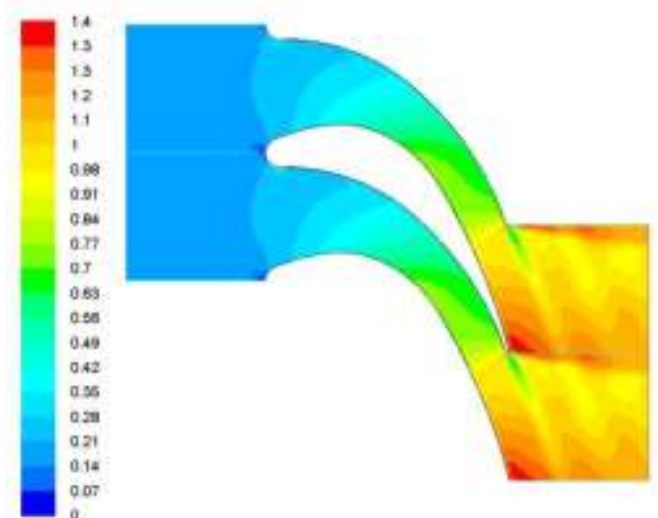

(e)

Figure 13. Contours of Mach number: (a) Base profile, (b) $C_{1}$, (c) $C_{2}$, (d) $C_{3}$, (e) $C_{4}$ 


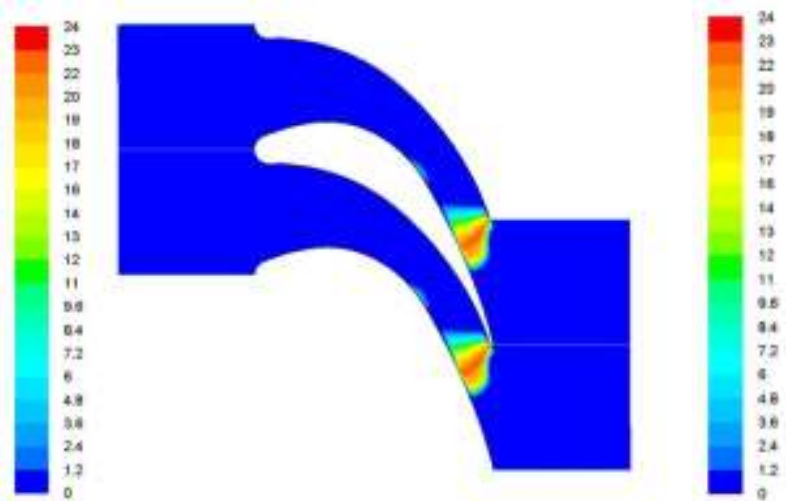

(a)
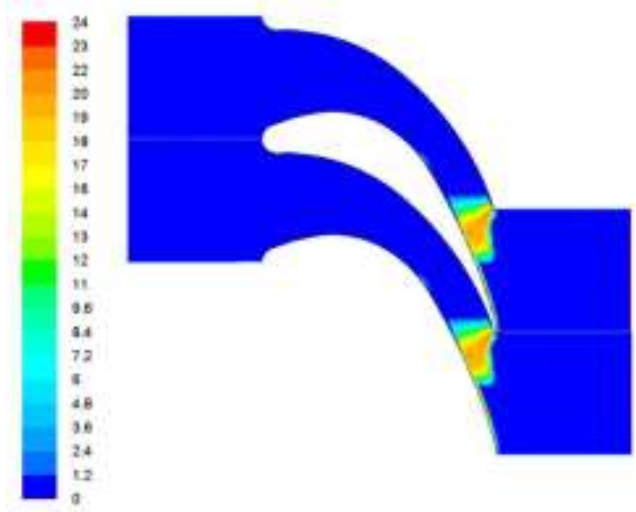

(c)

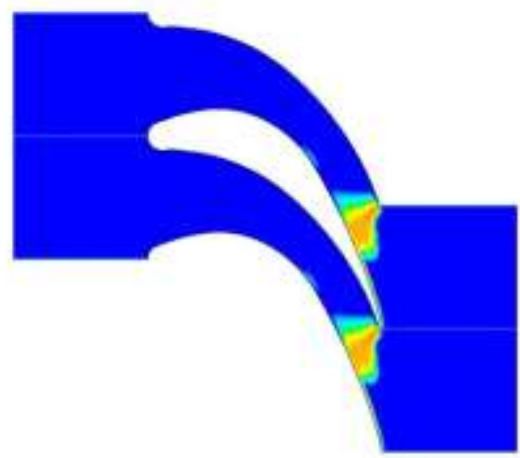

(b)

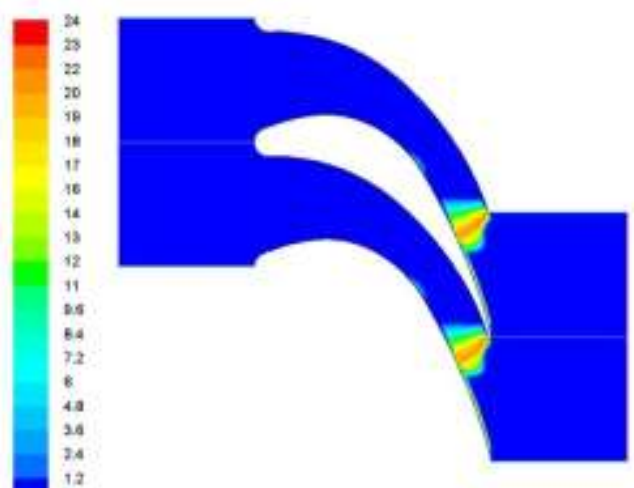

(d)

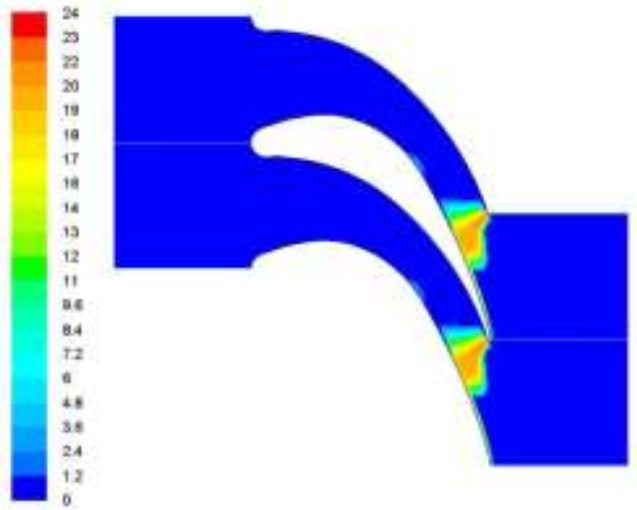

(e)

Figure 14. Contours of nucleation rate: (a) Base profile, (b) $C_{1}$, (c) $C_{2}$, (d) $C_{3}$, (e) $C_{4}$ 


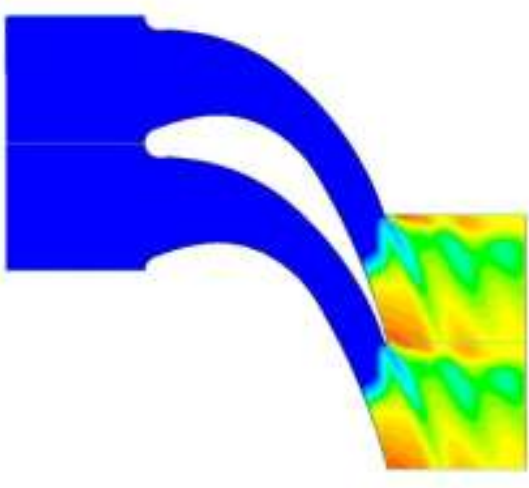

(a)

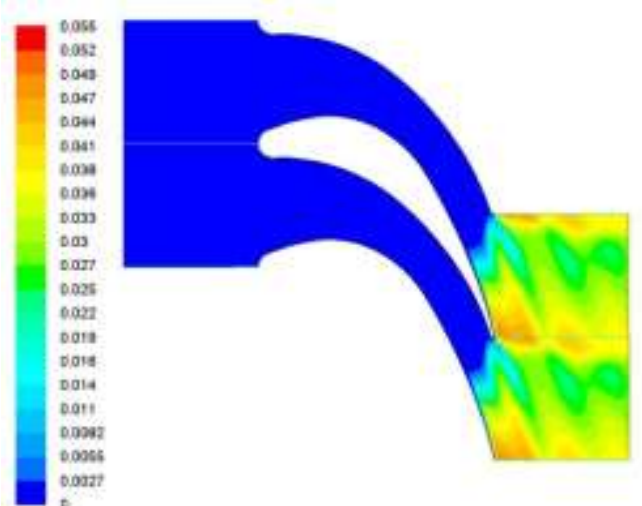

(c)

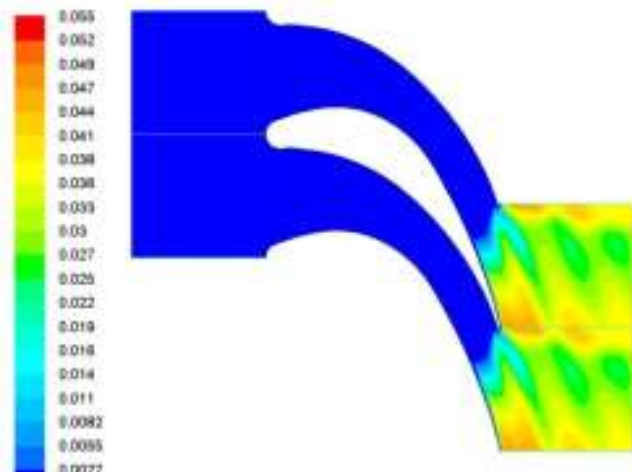

(b)

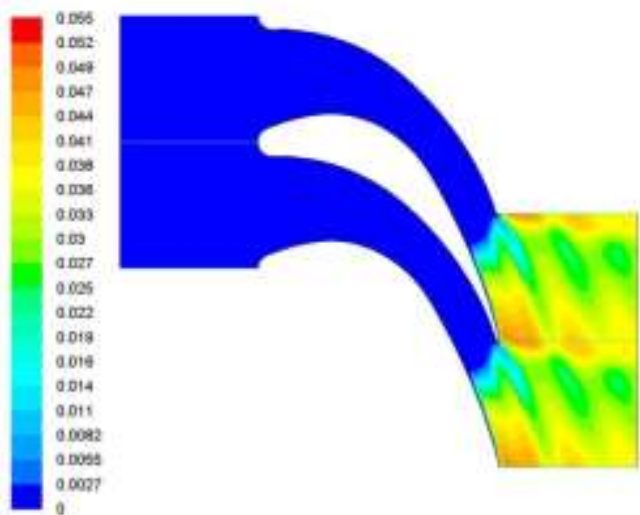

(d)

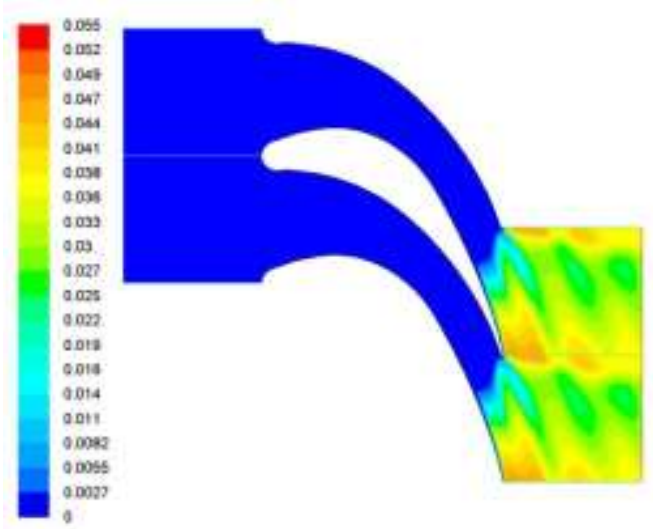

(e)

Figure 15. Contours of liquid mass fraction: (a) Base profile, (b) $C_{1}$, (c) $C_{2}$, (d) $C_{3}$, (e) $C_{4}$ 
The contours of nucleation rate are depicted in Fig. 14. Although the location of nucleating region remains intact after optimization of the blade profile (the nucleation sites are constricted in a narrow region around the cascade throat and the nucleation starts on the suction side near the point of shock wave impingement), the nucleation rate reduces considerably for optimized profiles. Reduction in nucleation rate is obtained by the modification of expansion rate within the blade cascade during the shape optimization process. Another noticeable trend for optimized profile is the formation of a thin layer adjacent to the suction surface of blade with moderate nucleation rate.

Finally, as it can be seen in Fig. 15, optimization of the blade profile regardless of the objective function suppresses the non-equilibrium condensation and reduces the liquid mass fraction. Furthermore, the optimization of the blade profile shrinks and isolates the regions with considerable water content immediately after the trailing edge of the blade.

\subsubsection{Baumann factor}

A classical approach for quantifying wetness losses is the Baumann rule [35] in which the wet total isentropic efficiency $\left(\eta_{\mathrm{s}}\right)$ is measured against the dry isentropic efficiency $\left(\eta_{\mathrm{s}, \mathrm{dry}}\right)$. Mathematical formulation of Baumann rule is given by,

$$
\eta_{\mathrm{s}}=\eta_{\mathrm{s}, \mathrm{dry}}\left(1-\alpha_{\mathrm{dry}} \overline{\mathrm{y}_{\mathrm{m}}}\right)
$$

where $\left(\alpha_{\text {dry }}\right)$ is the Baumann factor and $\left(\overline{y_{m}}\right)$ is the mean wetness fraction. Dry isentropic efficiency is defied for a dry expansion between inlet and outlet pressures identical to the wet expansion, but adequately elevated inlet temperature to eliminate condensation within blade cascade. For all the optimization cases considered in the manuscript, dry isentropic efficiency is 
around $92.38 \%$ and using this value the Baumann factor is calculated using Eq. 24 and presented in table 4. As it can be seen, the Baumann factors of optimized profiles are lower than the corresponding value for the base blade profile; A fact that further highlights the success of our proposed shape optimization process in wetness loss reduction for the Dykas's turbine blade cascade. A maximum $10 \%$ reduction in Baumann factor is reported for the case $\mathrm{C}_{3}$.

Table 4. Baumann factor for optimized profiles

\begin{tabular}{|cccccc|}
\hline Case & Base Profile & $\mathbf{C}_{\mathbf{1}}$ & $\mathbf{C}_{\mathbf{2}}$ & $\mathbf{C}_{\mathbf{3}}$ & $\mathbf{C}_{\mathbf{4}}$ \\
\hline Baumann Factor & 1.3870 & 1.2653 & 1.2714 & 1.2469 & 1.2718 \\
\hline
\end{tabular}

\subsubsection{Comparison between optimization in dry and wet conditions}

To further investigate the effect of non-equilibrium condensation on the outcome of turbine blade shape optimization, the profile of Dykas's blade cascade is optimized in dry and wet flow conditions with identical overall pressure ratios. Dry flow condition is obtained by raising the inlet temperature of steam in order to completely eliminate the condensation within the cascade. A comparison between these two set of results became possible by using the ratio of lift to drag forces as the objective function of the shape optimization. The optimal profiles of steam turbine blade in dry and wet flow conditions are compared to each other in Fig. 16. As it can be seen, near the leading edge of the turbine blade, the profile is modified more significantly during the optimization process for wet condition in order to restrain the local expansion rate and suppress the spontaneous nucleation. At the trailing edge, the optimal profile in wet condition is thinner than the corresponding profile for dry condition. This alteration in optimal blade profile for wet condition in respect to the base profile increases the throat area of the cascade and elevates the local fluid pressure and subsequently constrains the nucleation rate and droplet growth. 
Finally, as it presented in table 5, there is a greater potential for improving blade cascade efficiency in wet conditions. Nevertheless, the isentropic efficiency of blade cascade is lower in the presence of non-equilibrium condensation in comparison to corresponding dry steam flow across the cascade.

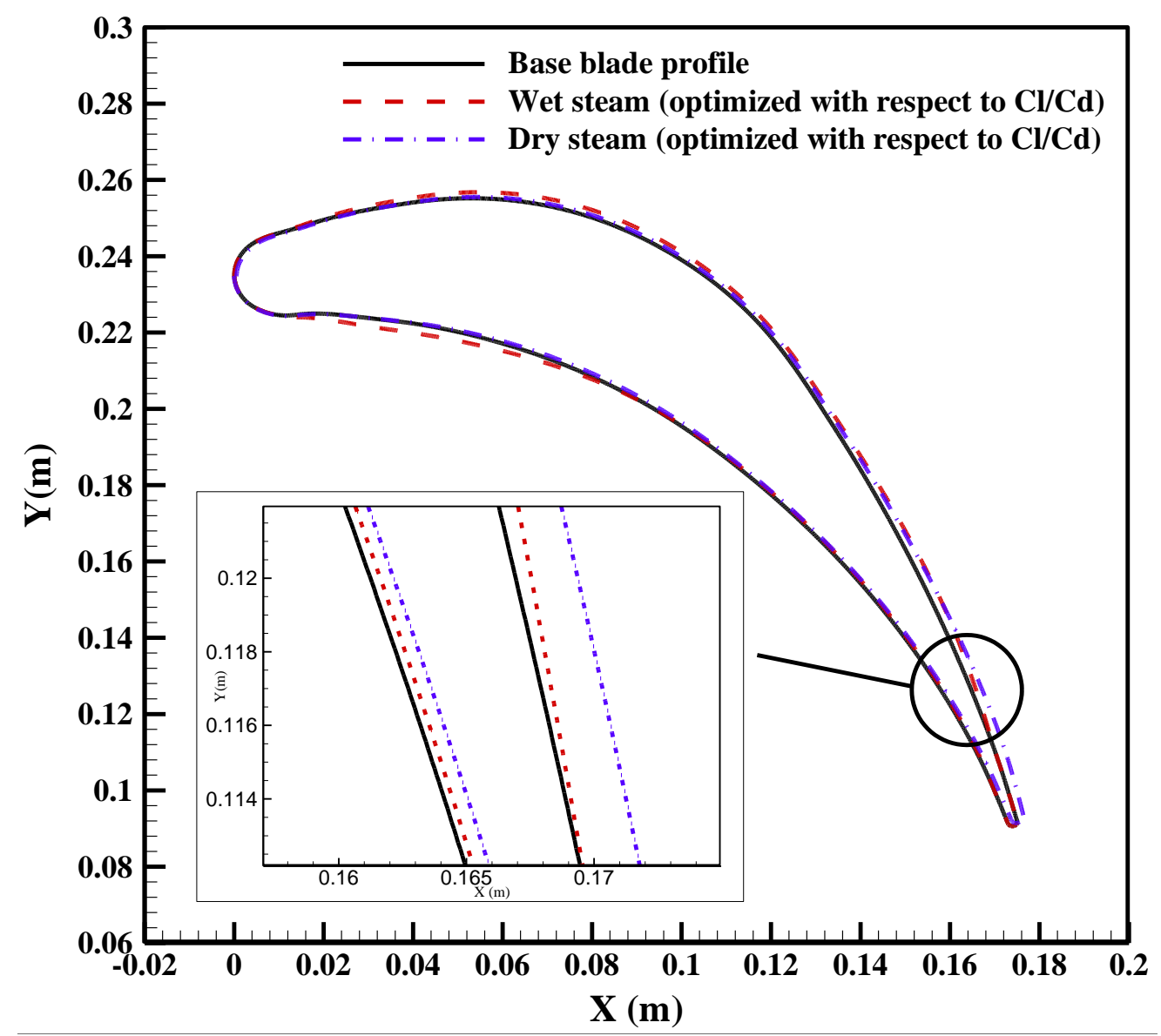

Figure 16. Optimal blade profiles for wet and dry flow conditions

Table 5. Comparison between optimization in dry and wet conditions in respect to $\left(\mathrm{F}_{\text {lift }} / \mathrm{F}_{\mathrm{drag}}\right)$

\begin{tabular}{|cccc|}
\hline Case & $\begin{array}{c}\text { Base isentropic } \\
\text { efficiency }(\boldsymbol{\%})\end{array}$ & $\begin{array}{c}\text { Optimal isentropic efficiency } \\
(\boldsymbol{\%})\end{array}$ & $\begin{array}{c}\text { Increase in efficiency } \\
(\boldsymbol{\%})\end{array}$ \\
\hline Dry Condition & 92.4 & 92.7 & 0.32 \\
Wet Condition & 89.9 & 90.3 & 0.45 \\
\hline
\end{tabular}




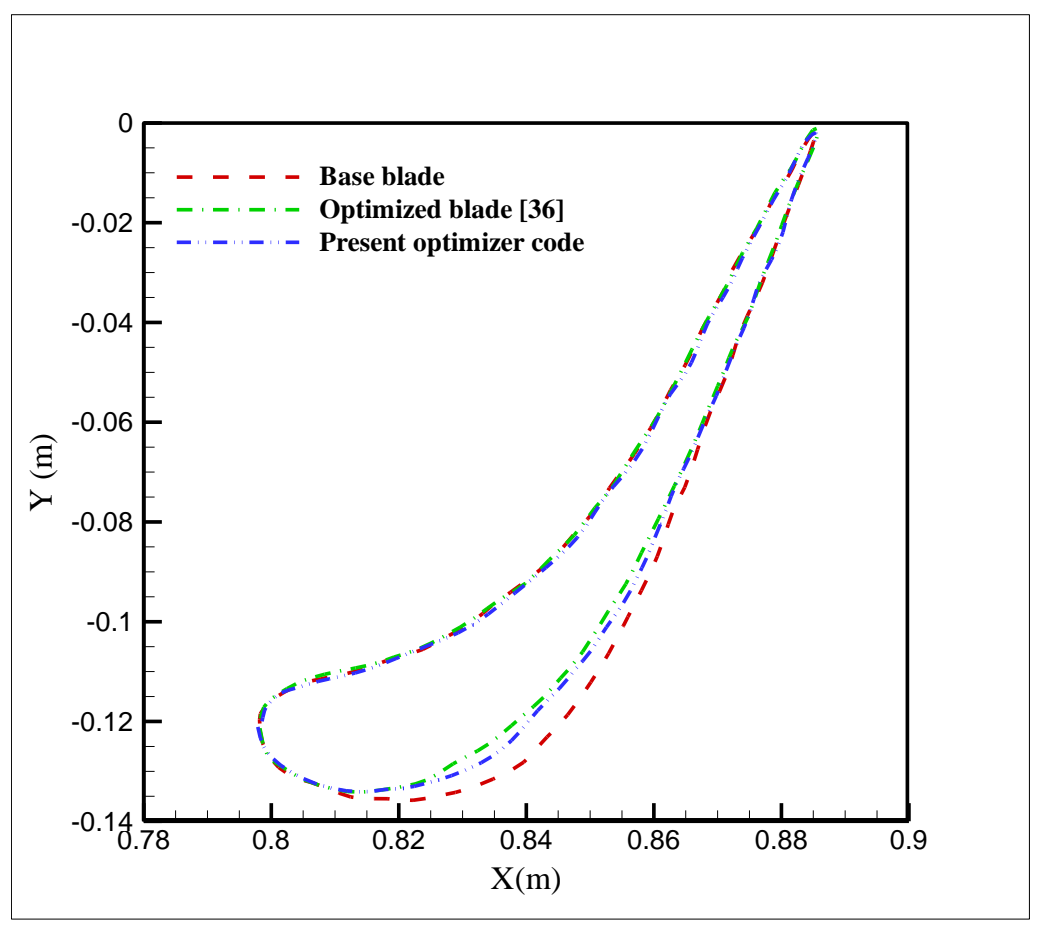

(a)

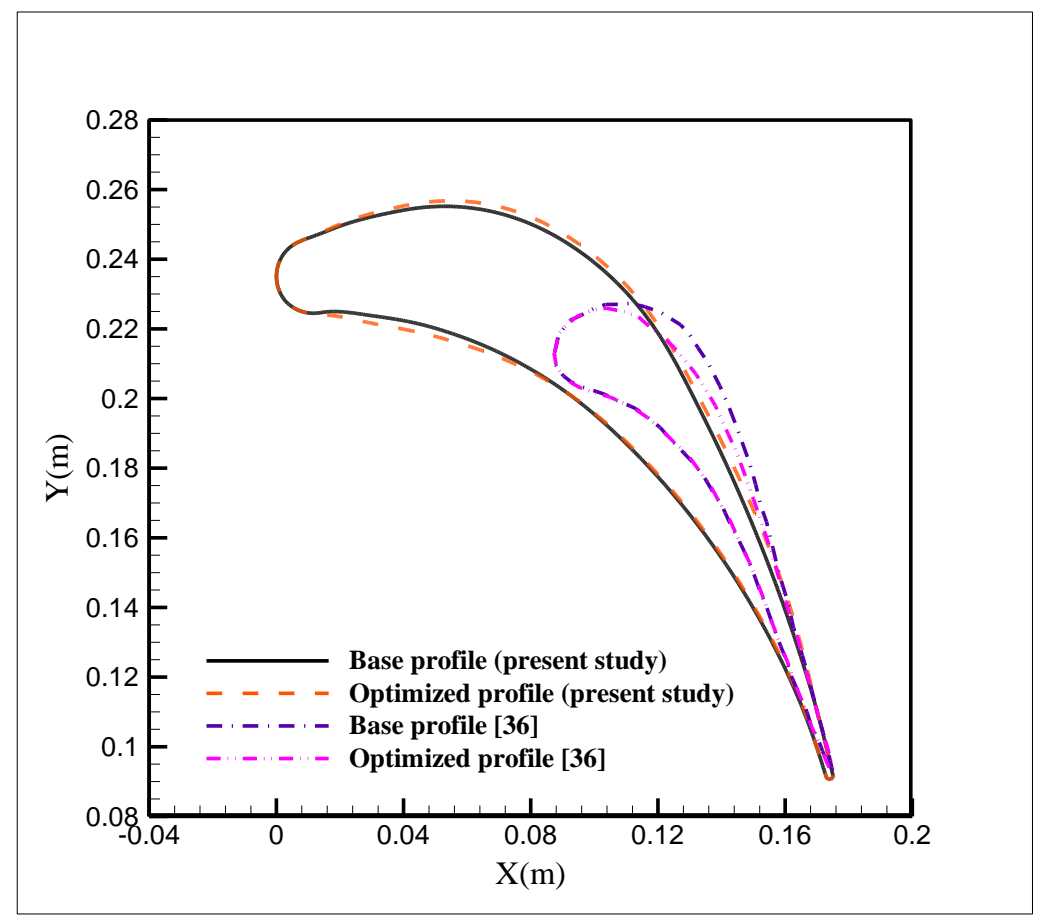

(b)

Fig. 17. Comparison between present optimization methods for non-condensing flow (a) profile of Luo et al. [36] (b) present profile and the profile of Luo et al. [36]. 
Fig. 17 (a) shows the comparison between the previous optimization method of [36] and the present optimizer code in non-condensing flow. The results show that both optimizer approaches act mainly on the leading edge and their performances are somehow similar to each other. This result also can approve the accuracy of the present optimizer method. In Fig. 17 (b) a comparison between the present optimization result and the result of [36] is presented for non-condensing flow. Although the blade profiles are different, one interesting result can be concluded. In noncondensing flows, the optimization mainly acts on the leading edge (of course when there is no sign of separation). But in condensing flow the main modification is made in the trailing edge in where the two-phase flow exists.

\section{Conclusion}

In this work, the shape optimization of a $3 \mathrm{~d}$ nozzle and a $2 \mathrm{~d}$ turbine blade cascade was presented based on CFD simulation of turbulent nucleating transonic wet steam flow in the corresponding flow passage. Both the liquid and gaseous phases were treated as continua and for each phase the conservation laws were solved together with proper source terms modeling the mass transfer and momentum exchange between two phases. A non-equilibrium condensation model based on classical nucleation and growth theory was utilized as well. For both geometries considered in this study, various objective functions were examined and compared to each other. The major findings of the research is organized as,

\section{(a) Moore's "Nozzle A":}

- Shape of optimized nozzle profiles deviates noticeably from its linear base profile especially near the flow outlet. 
- Based on REG, the best suited target function for the nozzle shape optimization is the nucleation rate for which $81 \%$ and $15 \%$ reduction in entropy generation rate and droplet radius is reported against the base nozzle.

- Using maximum droplet radius as the objective function results in $59 \%$ reduction in the maximum droplet radius within the optimized Moore's "Nozzle A".

- Each shape optimization attempt suppressed the non-equilibrium condensation and weakens the condensation shock.

- Shape optimization delays the on-set of nucleation and restricts the growth of water droplets to a certain degree.

- $\quad$ Liquid mass fraction is reduced for the optimized nozzle profiles.

(b) Dykas's Turbine Blade Cascade,

- Shape optimization alters the blade profile in the vicinity of its trailing edge where active nucleation sites exist.

- The most successful shape optimization scenario is achieved by using maximum droplet radius as the objective function. $34 \%$ REG and $2.1 \%$ increase in blade efficiency is attained.

- Optimization of blade profile modifies the expansion rate across blade cascade and diminishes the condensation shock.

- Shape optimization reduces the Mach number at the trailing edge of the blade and weakens the oblique shock wave originated from the region.

- The nucleation rate and liquid mass fraction is lowered for optimized profiles.

- Baumann factor reduces after each shape optimization attempt. A maximum $10 \%$ reduction is reported. 
- The second best optimization scenario is achieved with liquid mass fraction as the target function.

- Shape optimization forms a thin layer adjacent to the blade surface with moderate nucleation sites.

Finally, k- $\omega$ SST turbulence model more accurately predicts the wet steam flow field in comparison to the well-known k- $\varepsilon$ model for Moore's "Nozzle A" and Dykas's turbine blade cascade.

\section{References}

[1] J.A. Hesketh, P.J. Walker, Effects of wetness in steam turbines, Proc. IMechE, 219 (2005) 1301-1314.

[2] A.J. White, J.B. Young, P.T. Walters, Experimental validation of condensing flow theory for a stationary cascade of steam turbine blade, Phil. Trans. R. Soc. Lond. A, 354 (1996) 59-88.

[3] Moses, C.A., Stein, G.D., 1978. On the growth of steam droplets formed in a Laval nozzle using both static pressure and light scattering measurements. J. Fluids Eng. 100, 311-322.

[4] P.G. Hill, Condensation of water vapor during supersonic expansion in nozzles, J. Fluid Mech. 25 (1966) 593620 (Part 3).

[5] F. Bakhtar, D.J. Ryley, K.A. Tubman, J.B. Young, Nucleation studies in flowing high pressure steam, Inst. Mech. Eng. 189 (1975) 427-436.

[6] A.G. Gerber, M.J. Kermani, A pressure based Eulerian-Eulerian multi-phase flow model for non-equilibrium condensation in transonic flow, Int. J. Heat and Mass Trans., 47 (2004) 2217-2231. 
[7] S. Dykas, W. Wroblewski, H. Luckowicz, Prediction of losses in the flow through the last stage of low-pressure steam turbine, Int. J. Numer. Meth. Fluids, 53 (2007) 933-945.

[8] B. Nikkhahi, M. Shams, M. Ziabasharhagh, A numerical investigation of two-phase stem flow around a 2-D turbine's rotor tip, Int. Comm. Heat and Mass Transfer, 36 (2009) 632-639.

[9] W. Wroblewski, S. Dykas, A. Gardzilewicz, M. Kolovratnik, Numerical and Experimental Investigations of Steam Condensation in LP Part of a Large Power Turbine, J. Fluid Engineering, 131 (2009).

[10] W. Wroblewski, S. Dykas, A. Gepert, Steam condensing flow modeling in turbine channels, Int. J. Multiphase Flow, 35 (2009) 498-506.

[11] A.H. Yousif, A.M. Al-Dabagh, R.Ch. Al-Zuhairy, Non-equilibrium spontaneous condensation in transonic steam flow, Int. J. Therm. Sci., 68 (2013) 32-41.

[12] S. Dykas, W. Wroblewski, Two-fluid model for prediction of wet steam transonic flow, Int. J. Heat Mass Transf. 60 (2013) 88-94.

[13] Y. Xinggang, X. Danmei, W. Cong, W. Chun, N. Chu, Numerical investigation of condensing flow in the last stage of low-pressure nuclear steam turbine, Nuc. Eng. Des. 275 (2014) 197-204.

[14] X. Yu, Z. Xiao, D. Xie, Ch. Wang, Co. Wang, A 3D method to evaluate moisture losses in a low pressure steam turbine: application to a last stage, Int. J. Heat Mass Transf. 84 (2015) 642-652.

[15] S. Dykas, M. Majkut, M. Strozik, K. Smolka, Experimental study of condensing steam flow in nozzles and linear blade cascade, Int. J. Heat Mass Transf. 80 (2015) 50-57

[16] M. Giordano, P.M. Congedro, P. Cinnella, Nozzle Shape Optimization for Wet-Steam Flows, 19th Computational Fluid Dynamics Conference, 22-25 June 2009, San Antonio. 
[17] S.J. Keisari, M. Shams, Shape optimization of nucleating wet-steam flow nozzle, Applied Thermal Engineering (2016), DOI: http://dx.doi.org/10.1016/j.applthermaleng.2016.04.134.

[18] S. M. A. Noori Rahim Abadi, R. Kouhikamali, K. Atashkari, Two-fluid model for simulation of supersonic flow of wet steam within high-pressure nozzles, Int. J. Therm. Sci. 96 (2015) 173-182.

[19] S. M. A. Noori Rahim Abadi, R. Kouhikamali, K. Atashkari, Non-equilibrium condensation of wet steam flow within high-pressure thermo-compressor, Appl. Therm. Eng. 81 (2015) 74-82.

[20] S.M.A. Noori Rahim Abadi, R. KouhikamalI, CFD-aided mathematical modeling of thermal vapor compressors in multiple effects distillation units, Appl. Math. Mod., DOI: http://dx. 10.1016/j.apm.2016.02.032

[21] S. Dykas, W. Wroblewski, Single- and two-fluid models for steam condensing flow modeling, Int. J. Multi. Flow 37 (2011) 1245-1253.

[22] F. R. Menter. Two-Equation Eddy-Viscosity Turbulence Models for Engineering Applications, AIAA Journal 32 (1994) 1598-1605.

[23] Z. Yang, T. H. Shih, New time scale based k-E model for near wall turbulence. AIAA J. 31 (1993) 1191-1197.

[24] A. R. Avetissian, G. A. Philippov, L. I. Zaichik, Effects of turbulence and inlet moisture on two-phase spontaneously condensing flows in transonic nozzles, Int. J. Heat Mass Transf. 51 (2008) 4195-4203.

[25] A. R. Avetissian, G.A. Philippov, L. I. Zaichik, The effect of turbulence on spontaneously condensing wetsteam flow, Nuclear Eng. and Des. 235 (2005) 1215-1223.

[26] W. Wagner, The IAPWS Industrial Formulation 1997 for the thermodynamic properties of water and steam, Transactions of the ASME, J. Eng. Gas Turbines Power 122 (2000). 
[27] M. E. Deich, V.F. Stepanchuk, G.A. Saltanov, Calculating of the rate of formation of condensation centers in supersaturated vapor, heat transfer - Soviet, Research 12 (1969) 106-111.

[28] J. Young, The condensation and evaporation of liquid droplets at arbitrary Knudsen number in the presence of an inert gas, Int. J. Heat Mass Transf. 36 (1993) 2941-2956.

[29] K. Deb, A. Pratap, S. Agarwal, T. Meyarivan. A fast and elitist multi-objective genetic algorithm, NSGA-II. IEEE Trans. Evol. Comput.6 (2002) 182-97.

[30] K. Deb, Multi-objective optimization using evolutionary algorithms; 2001.

[31] M. Mitchell, An Introduction to Genetic Algorithms, The MIT Press, Cambridge, 1998.

[32] M. Arbnia, Aerodynamic Shape Optimization of Axial Turbines in Three Dimensional Flow, PhD Thesis, Concordia University Canada; 2012.

[33] J. Smolka, CFD-based 3-D optimization of the mutual coil configuration for the effective cooling of an electrical transformer, Appl. Therm. Eng. 50 (2013) 124-133.

[34] M.J. Moore, C.H. Severing, Phase Steam Flow in Turbines and Separators, Hemisphere Publishing Corporation, Washington, 1976.

[35] K. Baumann, Some recent developments in large steam turbine practice, J. Inst. Electr. Eng. 59 (1921) 565-623.

[36] J. Luo, J. Xiong, , F. Liu, I. McBean, Three-Dimensional Aerodynamic Design Optimization of a Turbine Blade by Using an Adjoint Method, J. Turbomach. (2011) 133, 011026. 